OPEN ACCESS

Edited by:

Benyi Li,

University of Kansas Medical Center,

United States

Reviewed by:

Jiajia Zhao,

Huazhong University of Science and

Technology, China

Arjun Singh,

Memorial Sloan Kettering Cancer

Center, United States

Qi Ma,

Ningbo First Hospital, China

*Correspondence:

Qingming Tang

hust_tang@hust.edu.cn

Xiaozhao Zhang

zxz5360_1988@163.com

${ }^{\dagger}$ These authors have contributed equally to this work

Specialty section:

This article was submitted to Pharmacology of Anti-Cancer Drugs, a section of the journa

Frontiers in Pharmacology

Received: 14 July 2021 Accepted: 25 November 2021

Published: 13 December 2021

Citation:

Zhou J, Wang J, Zhang X and Tang Q (2021) New Insights Into

Cancer Chronotherapies.

Front. Pharmacol. 12:741295.

doi: 10.3389/fphar.2021.741295

\section{New Insights Into Cancer Chronotherapies}

\author{
Jingxuan Zhou ${ }^{1,2,3 t}$, Jiechen Wang ${ }^{1,2,3 \dagger}$, Xiaozhao Zhang ${ }^{4,5 *}$ and Qingming Tang ${ }^{1,2,3 *}$ \\ ${ }^{1}$ Department of Stomatology, Union Hospital, Tongji Medical College, Huazhong University of Science and Technology, Wuhan, \\ China, ${ }^{2}$ School of Stomatology, Tongji Medical College, Huazhong University of Science and Technology, Wuhan, China, ${ }^{3}$ Hubei \\ Province Key Laboratory of Oral and Maxillofacial Development and Regeneration, Wuhan, China, ${ }^{4}$ Beijing Tongren Eye Center, \\ Beijing Tongren Hospital, Capital Medical University, Beijing, China, ${ }^{5}$ Beijing Institute of Ophthalmology, Beijing Tongren Hospital, \\ Capital Medical University, Beijing, China
}

Circadian clocks participate in the coordination of various metabolic and biological activities to maintain homeostasis. Disturbances in the circadian rhythm and cancers are closely related. Circadian clock genes are differentially expressed in many tumors, and accelerate the development and progression of tumors. In addition, tumor tissues exert varying biological activities compared to normal tissues due to resetting of altered rhythms. Thus, chronotherapeutics used for cancer treatment should exploit the timing of circadian rhythms to achieve higher efficacy and mild toxicity. Due to interpatient differences in circadian functions, our findings advocate an individualized precision approach to chronotherapy. Herein, we review the specific association between circadian clocks and cancers. In addition, we focus on chronotherapies in cancers and personalized biomarkers for the development of precision chronotherapy. The understanding of circadian clocks in cancer will provide a rationale for more effective clinical treatment of tumors.

Keywords: circadian clocks, circadian rhythms, cancers, chronotherapies, personalized chronotherapies 3

\section{INTRODUCTION}

Circadian clocks exist in biological organisms and serve as a method to adapt to natural environmental changes. Circadian clocks consist of the suprachiasmatic nucleus (SCN) and peripheral clocks. When variations in environmental light or other stimuli occur based on the laws of nature, the $\mathrm{SCN}$ recognizes these changes and inputs signals to specific pathways so that subordinate clocks receive the correct messages to make the corresponding adjustments to the 24-h cycle (Shafi and Knudsen, 2019; Kinouchi and Sassone-Corsi, 2020). Studies over the last decade have shown that circadian clocks regulate various physiological activities and are essential to our health. At the complex multicellular and molecular level, circadian clocks participate in the evolutionary machinery that stipulates the temporal adjustment of physiology to maintain homeostasis through the establishment of circadian rhythms. Any disruption gives rise to many chronic diseases, such as metabolic disorders and malignant tumors.

Evidence has shown there is a strong interaction between tumors and circadian clocks. The clock genes, which generate oscillatory signals transmitted to the molecular clocks, are altered in different cancers. Further, clock genes whose expression is dysregulated may act as driving factors in carcinogenesis and cancer progression. Our research group demonstrated that brain and muscle aryl hydrocarbon receptor nuclear translocator1 (BMAL expression presents rhythmic oscillation and is closely associated with the development of oral squamous cell carcinoma (OSCC). A genetically engineered mouse lung tumor model was used to demonstrate that disruption of 


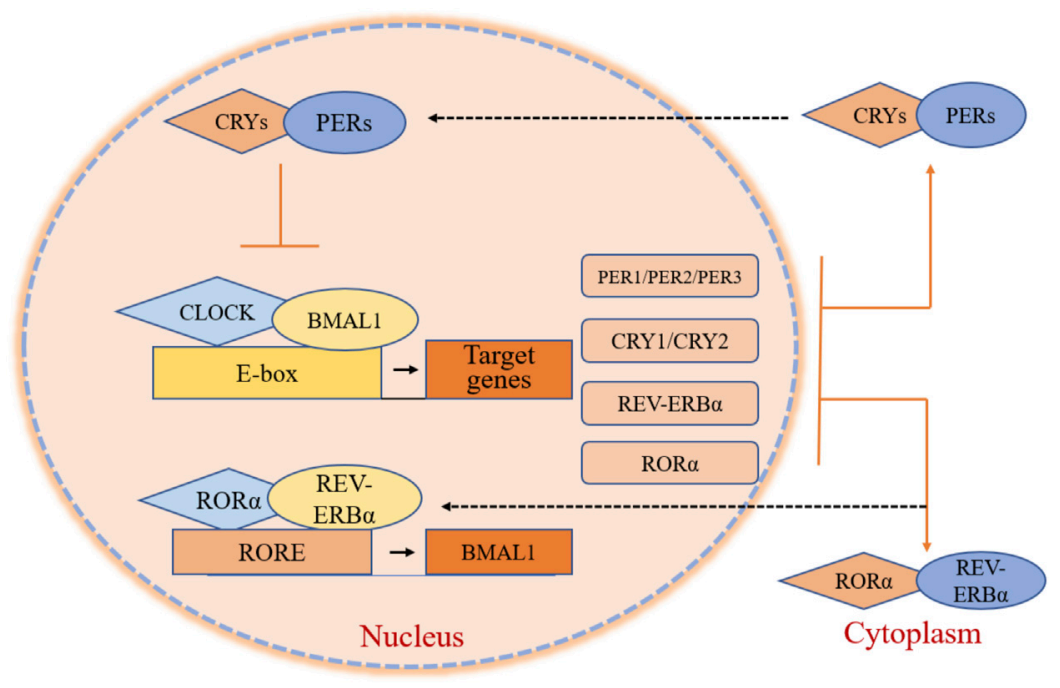

FIGURE 1 | Core clock gene organization in circadian clocks. BMAL1 and CLOCK are transcription factors that contain two helix-loop-helix domains and bind E-box elements in the $P E R, C R Y, R E V-E R B \alpha$, and $R O R \alpha$ genes, influencing positively on circadian transcription. $P E R$ and $C R Y$ form heterodimers, interacting with casein kinase $l_{\varepsilon}(\mathrm{CKl} \varepsilon)$ and translating into the nucleus. These two genes negatively mediate BMAL1/CLOCK-driven transcription. $R O R \alpha$ and $R E V$ - $E R B \alpha$ activate and repress the transcription of BMAL1 through their competitive action on response elements (RORES) on the BMAL1 promoter.

circadian rhythms could promote lung tumor growth and decrease survival (Papagiannakopoulos et al., 2016). Oncogenic processes weaken or disrupt circadian rhythms (Huang et al., 2011). In addition, tumor tissues reset their circadian rhythms compared with normal tissues. Thus, chronotherapies could improve efficacy and alleviate biotoxicity in tumor treatments if differences in circadian rhythms are considered during drug administration.

Generally, chronotherapies depend on the circadian timing system (CTS) that controls circadian rhythms involving metabolism and biological activities (Cederroth et al., 2019). Accumulating evidence has shown that providing rhythmic treatments can not only avoid some of the side effects associated with cancer therapy but this approach can also improve prognosis, for example, administering a drug at a specific time can reduce changes in its metabolism and in patient fatigue (Ozturk et al., 2017; Shuboni-Mulligan et al., 2019; Sulli et al., 2019). However, some dosage regimens for traditional treatments are not aligned to the individual characteristics of cancer patients due to differences in circadian rhythms between normal and tumor tissues. Precise and optimal timing is required to exploit personalized chronotherapeutic delivery for each individual (Ozturk et al., 2017). Thus, potential molecular targets or biomarkers have been investigated to determine real-time dosing regimens. One such marker investigated by our group is BMAL1, which presents stable rhythmic oscillations and is considered a target for treatment with relevant anticancer drugs at a specific timepoint. How to identify personalized indicators that can be applied to chronotherapies has become a crucial question.

This review summarizes the expression patterns of clock genes in tumors and describes studies in which the biological activities of cancer rhythms are closely associated with circadian clocks and tumors. We also focus on the mechanisms and specific treatments using the chronotherapy approach in existing studies and applications. In addition, personalized biomarkers with constant rhythms such as BMAL1 and temperature are of great concern. Based on these characteristics, we can provide an optimized treatment plan for individual cancer patients with improved efficacy.

\section{THE CORRELATION BETWEEN THE CIRCADIAN CLOCK AND TUMOR BIOLOGY Expression Patterns of Clock Genes are Variable in Tumors}

At the molecular level, in the BMAL1 and circadian locomotor output cycles kaput (CLOCK) act as transcription factors. They include two essential helix-loop-helix domains and bind E-box elements (CACGTG) in the Period (PER) and Cryptochrome $(C R Y)$ genes, which positively influence circadian transcription. $C R Y$ and $P E R$ form heterodimers that ineract with casein kinase $\mathrm{I} \varepsilon(\mathrm{CKI} \varepsilon)$. Both genes translocate into the nucleus to negatively mediate BMAL1/CLOCK-driven transcription (Figure 1) (Shearman et al., 2000). The alternations of clock gene expressions are closely connected with the occurrence and development of cancers. For brain tumors, the expression of CLOCK in high-grade glioma cells increases significantly compared with low-grade gliomas and non-gliomas, likely due to a decrease in miR-124 expression, which regulates RNA expression (Chen et al., 2013; Li A. et al., 2013). In one study, the expression of PER 2 and BMLA1 significantly decreased in OSCC tumors as evaluated by reverse transcription-quantitative PCR (RT-qPCR) and immunohistochemistry (Xiong et al., 2018). The same was observed in head and neck squamous cell 
carcinoma (HNSCC) and in nasopharyngeal carcinoma (Hou et al., 2020; Hsu et al., 2012; Rahman et al., 2019). CLOCK, PER1, as well as CRY levels, are also reduced in HNSCC. Compared to normal skin, patients with skin cutaneous melanoma (SKCM) present significant down-regulation in the expression of BMAL1, CRY1, CRY2, PER1, PER2, and PER3, and higher expression of CLOCK (de Assis et al., 2018), a similar pattern was also observed in patients with colon adenocarcinoma (COAD) (Fuhr et al., 2018; Krugluger et al., 2007; Neilsen et al., 2019). BMAL1 and PER3 levels increase, and CLOCK and CRY2 levels decrease in tissue samples obtained from follicular thyroid cancer (FTC) and papillary thyroid cancer (PTC) nodule tissues compared to benign tissues (Malaguarnera et al., 2020). In thymoma, only the level of PER1 decreases, while the expression of other clock genes all increase. In endometrial endometrioid carcinoma, PER2 is up-regulated nearly 15-fold in isolated esophageal tumors (Eca) with metastasis (Li et al., 2016). The expression of CLOCK is markedly increased in breast cancer, as increased expression of differentiated embryonic chondrogenic gene 1 (DEC1) has been associated with increased expression of estrogen receptor a (ERa), which binds to the CLOCK promotor to regulate its transcription (Xue et al., 2020), while BMAL1, PER, and CLOCK levels reduce. In previous studies, DEC1 overexpression in esophageal cancer, OSCC, and pancreatic ductal carcinoma also showed an associated increase in the expression of MIC-1, a p53-activated apoptosis factor. DEC1 interferes with cell apoptosis, and cancer cells become immortalized (Wu et al., 2012; Xu et al., 2012). However, in esophageal tumors, CLOCK, PER1, PER2, PER3, CRY1 as well as CRY2 levels are downregulated and their downstream proteins accordingly become disordered (van der Watt et al., 2020). As for lung cancer cells, the primary circadian gene CLOCK is up-regulated in CD133+ cells, and this can also be observed in A549 and H1299 cells (Jiang et al., 2020; Yoshida et al., 2013). A comparative analysis revealed that PER1 levels were nearly $30 \%$ those of normal tissues, PER2 was $70 \%, C R Y 1$ was $66 \%, C R Y 2$ was $30 \%$, and BMAL1 was $80 \%$ in non-small cell lung cancer (Chen et al., 2020). The downregulated expression of PER2 is attributed to the decrease in $\mathrm{Kmt} 2 \mathrm{~d}$ expression, a Histone methyltransferase that is suppressed in lung cancer cells (Alam et al., 2020; Yu et al., 2018). The expression of PER1, PER2, and CRY2 decrease in human fibrosarcoma and in undifferentiated pleomorphic sarcoma (Rivera-Reyes et al., 2018).The expression of BMAL1 and CLOCK are reduced in ovarian cancer due to the methylation of $\mathrm{CpG}$ sites on gene promoter regions (Gutiérrez-Monreal et al., 2016). Further, the expression of PER2 is reduced in ovarian cancer via inhibition of the PI3K (phosphatidylinositol 3-kinase) signaling pathway (Wang et al., 2020; Yeh et al., 2014). The altered expressions in ovarian cancer agree with adrenocortical carcinoma (ACC), cervical and endocervical cancer (CESC), uterine corpus endometrium carcinoma (UCEC), uterine carcinosarcoma (UCS), testicular germ cell tumors (TGCT), chronic myeloid leukemia (CML), liver hepatocellular carcinoma (LIHC), and prostate adenocarcinoma (PRAD) (Angelousi et al., 2020; Cao et al., 2009; Lin et al., 2008; Yang et al., 2006; Yang et al., 2009). The circadian genes show upregulated expression in pancreatic cancer, except for BMAL1 (Li et al., 2020; Relles et al., 2013). In contrast, the levels of common clock genes are decreased except for PER3 and CYR2 in cholangiocarcinoma. In kidney renal clear cell carcinoma (KIRC), the levels of BMAL1, (Human) Recombinant Protein (P01) (NR1D1), PER1, and PER2 are up-regulated, while CLOCK and CRY expression is down-regulated (Litlekalsoy et al., 2016; Zhou et al., 2020). The upregulation of $B M A L 1, C L O C K$, and $P E R$ in gastric cancer and the up-regulation of $C R Y 1$ in more advanced stage gastric cancer but not in the earlier stage has also been reported (Hu et al., 2014). In addition, in rectum adenocarcinoma (READ), BMAL1, PER1, PER3, and CRY levels decrease while CLOCK and PER2 levels increase (Lu et al., 2015). In acute myeloid leukemia (AML), PER2, PER3, and $C R Y$ levels are reduced due to reduced expression of CCAAT/enhancer-binding proteins (C/EBPs), while BMAL1, CLOCK, and PER1 levels increase(Gery et al., 2005). In lymphoid neoplasms, diffuse large B-cell lymphoma (DLBC), BMAL1, PER1, and PER2 levels are down-regulated, while CLOCK, PER3, and CRY levels show the opposite pattern (Table 1). Altogether, results demonstrate that the expression of clock genes varies in different types of tumor cells, and the disruption of clock rhythms is related to the occurrence and development of cancers (Gu et al., 2018; Verlande and Masri, 2019).

In contrast, the differential expression of clock genes may be associated with prognosis and survival of cancer patients. Patients with ACC or COAD exhibit low BMAL1 (ARNTL), which is associated with a higher overall survival rate over five or 10 years (Figure 2A). Inversely, patients with SKCM or KIRP show the opposite effects (Figure 2B). Furthermore, the expression of $B M A L 1$ is not associated with the survival of patients with BLCA and LUSC (Figure 2C). These findings suggest that the levels of clock genes play different roles across tumors and understanding their modulatory role can be advantageous to improve treatment strategies and predict the prognosis of cancer patients.

Nevertheless, there are still some issues that require further consideration, such as the oscillation in the expression of circadian clock genes in tumors. Our group tested the expression of BMAL1 at different time points in patients with tongue squamous cell carcinoma (TSCC) after being synchronized with dexamethasone (Tang et al., 2017). The results indicated that the expression of BMAL1 showed a stable cyclical fluctuation in TSCC. Further, BMAL1 also exhibited a phenomenon of circadian rhythm reset, reflected by a shorter phase and reduced oscillation amplitude. In murine mammary tumor cell lines, Per1 levels revealed a circadian rhythm with a 2.5-fold oscillation amplitude compared to normal tissues. However, in the liver, the daily maximum of Per 1 and Per 2 tumor expression was delayed by $4 \mathrm{~h}$. The oscillation amplitude of the rhythmic expression of Cry 1 decreases 5 -fold in tumors, and that of Bmal1 by 50 -fold (Yang et al., 2009). These investigations suggested that clock genes may be cancer-specific and that the circadian resets of these clock genes could be closely associated with subsequent chronotherapies. 
TABLE 1 | Variational expression of circadian clock genes in different types of cancers.

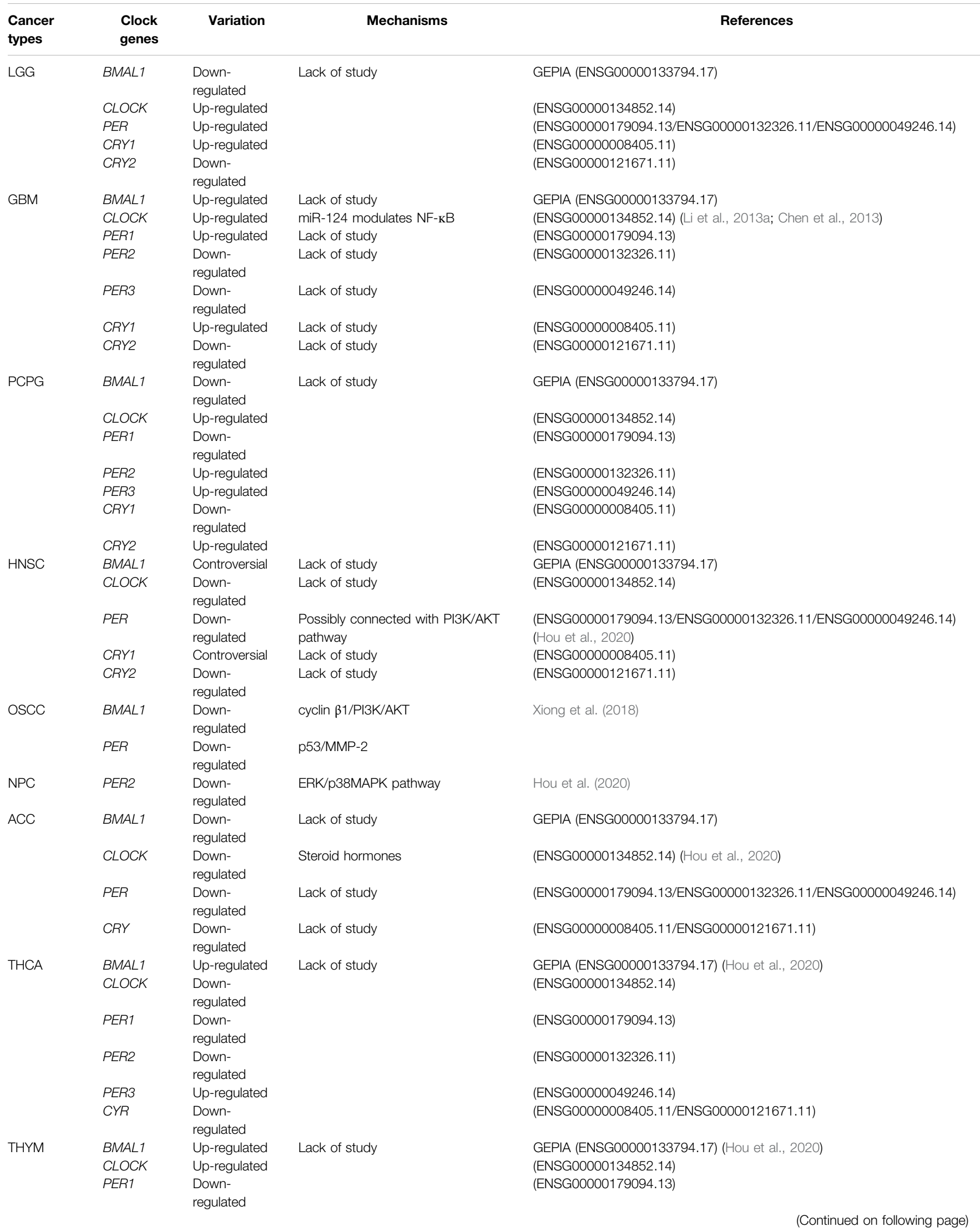


TABLE 1 | (Continued) Variational expression of circadian clock genes in different types of cancers.

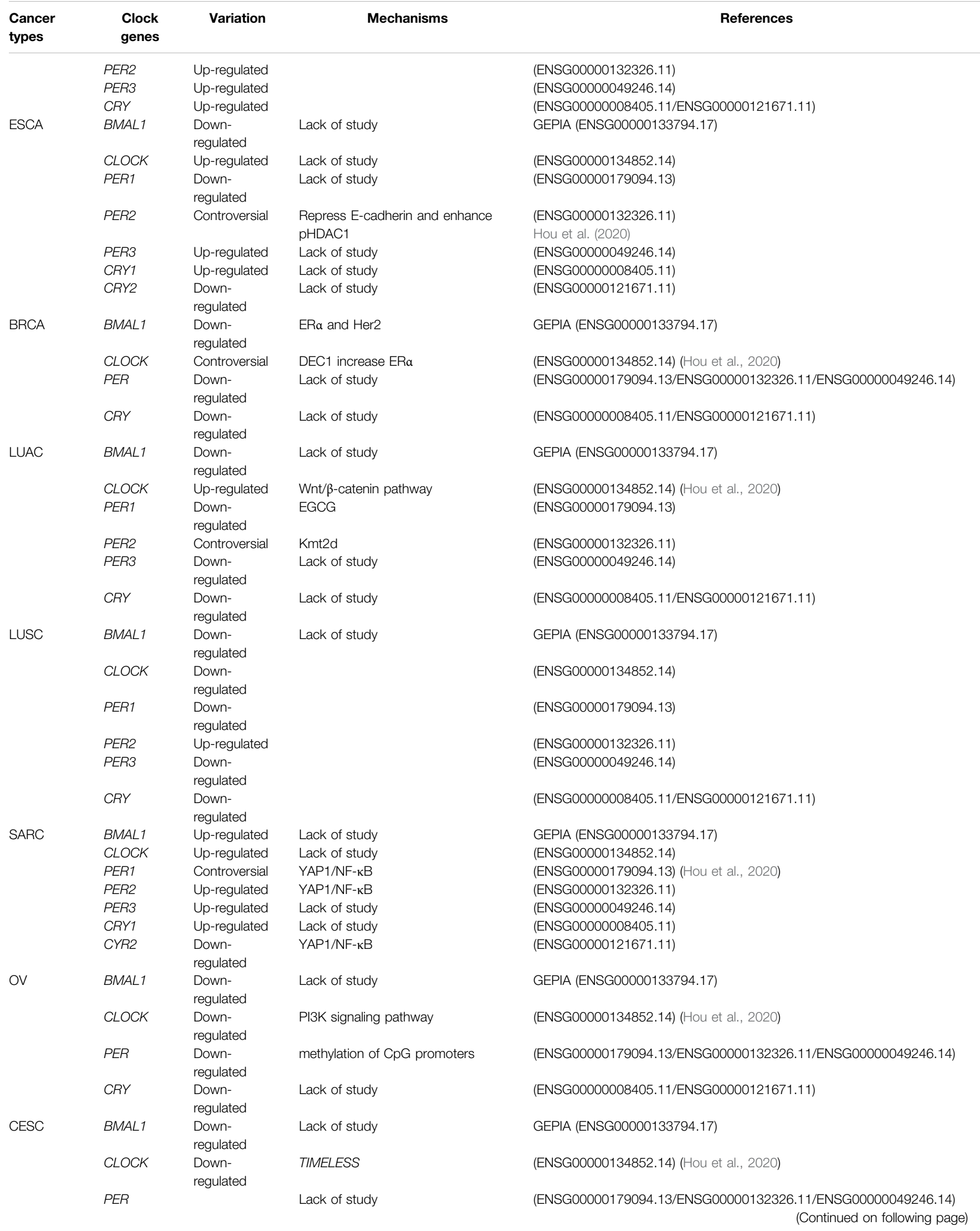


TABLE 1 | (Continued) Variational expression of circadian clock genes in different types of cancers.

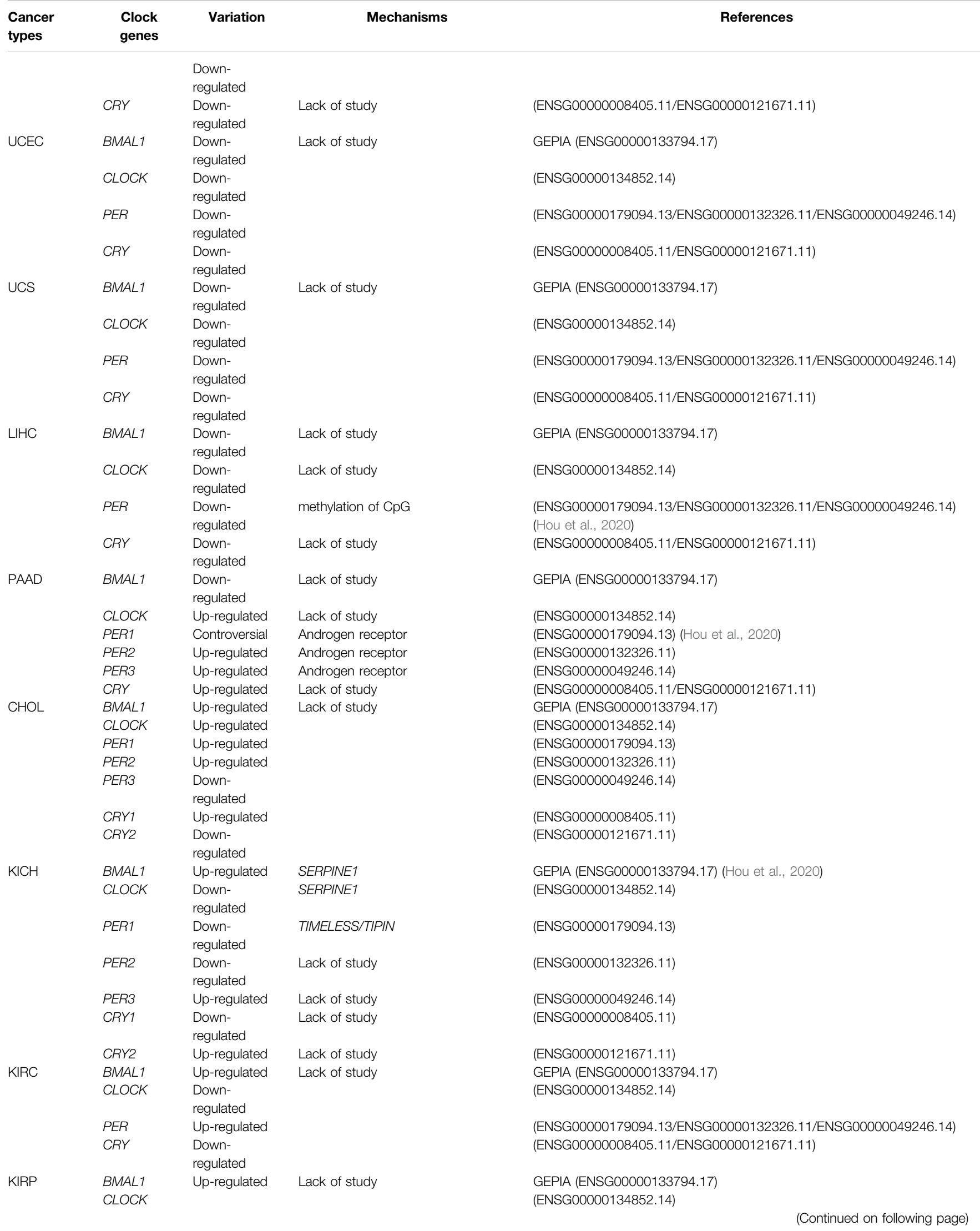


TABLE 1 | (Continued) Variational expression of circadian clock genes in different types of cancers.

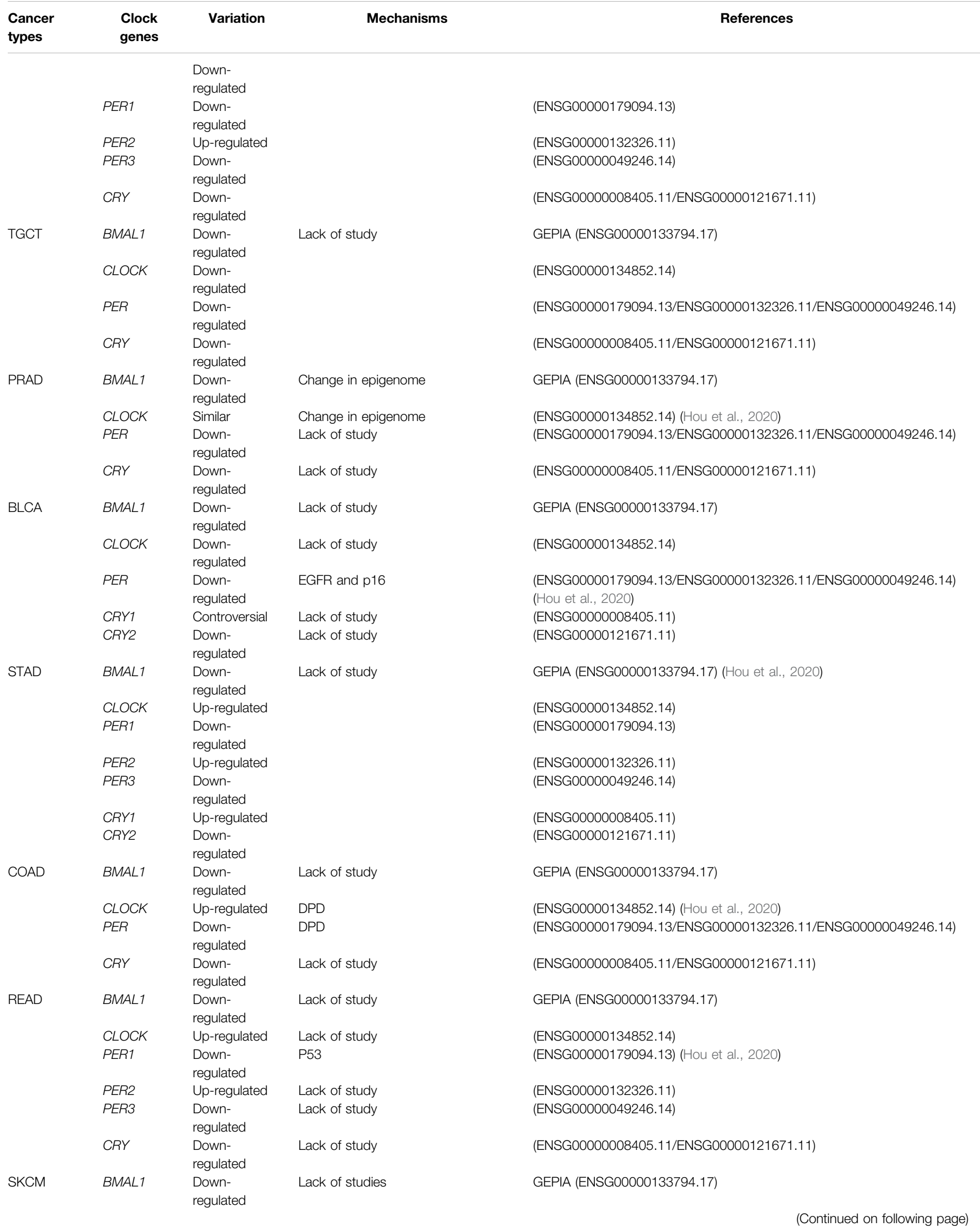


TABLE 1 | (Continued) Variational expression of circadian clock genes in different types of cancers.

\begin{tabular}{|c|c|c|c|c|}
\hline $\begin{array}{l}\text { Cancer } \\
\text { types }\end{array}$ & $\begin{array}{l}\text { Clock } \\
\text { genes }\end{array}$ & Variation & Mechanisms & References \\
\hline & CLOCK & Up-regulated & & (ENSG00000134852.14) (Hou et al., 2020) \\
\hline & PER & $\begin{array}{l}\text { Down- } \\
\text { regulated }\end{array}$ & & (ENSG00000179094.13/ENSG00000132326.11/ENSG00000049246.14) \\
\hline & CRY & $\begin{array}{l}\text { Down- } \\
\text { regulated }\end{array}$ & & (ENSG00000008405.11/ENSG00000121671.11) \\
\hline \multirow[t]{6}{*}{ AML } & $B M A L 1$ & Up-regulated & $\beta$-catenin & GEPIA (ENSG00000133794.17) \\
\hline & CLOCK & Up-regulated & C/EBPs & (ENSG00000134852.14) (Hou et al., 2020) \\
\hline & PER1 & Up-regulated & Lack of study & (ENSG00000179094.13) \\
\hline & PER2 & Controversial & Lack of study & (ENSG00000132326.11) \\
\hline & PER3 & $\begin{array}{l}\text { Down- } \\
\text { regulated }\end{array}$ & Lack of study & (ENSG00000049246.14) \\
\hline & $C R Y$ & $\begin{array}{l}\text { Down- } \\
\text { regulated }\end{array}$ & Lack of study & (ENSG00000008405.11/ENSG00000121671.11) \\
\hline \multirow[t]{4}{*}{ CML } & $B M A L 1$ & $\begin{array}{l}\text { Down- } \\
\text { regulated }\end{array}$ & Lack of study & GEPIA (ENSG00000133794.17) \\
\hline & CLOCK & $\begin{array}{l}\text { Down- } \\
\text { regulated }\end{array}$ & methylation of the $h P E R 3$ promoter & (ENSG00000134852.14) (Hou et al., 2020) \\
\hline & PER & $\begin{array}{l}\text { Down- } \\
\text { regulated }\end{array}$ & methylation of the $h P E R 3$ promoter & (ENSG00000179094.13/ENSG00000132326.11/ENSG00000049246.14) \\
\hline & CRY & $\begin{array}{l}\text { Down- } \\
\text { regulated }\end{array}$ & Lack of study & (ENSG00000008405.11/ENSG00000121671.11) \\
\hline \multirow[t]{6}{*}{ DLBC } & $B M A L 1$ & $\begin{array}{l}\text { Down- } \\
\text { regulated }\end{array}$ & C/EBPs & GEPIA (ENSG00000133794.17) (Hou et al., 2020) \\
\hline & CLOCK & Up-regulated & Lack of study & (ENSG00000134852.14) \\
\hline & PER1 & $\begin{array}{l}\text { Down- } \\
\text { regulated }\end{array}$ & Lack of study & (ENSG00000179094.13) \\
\hline & PER2 & Controversial & Lack of study & (ENSG00000132326.11) \\
\hline & PER3 & Up-regulated & Lack of study & (ENSG00000049246.14) \\
\hline & $C R Y$ & Up-regulated & Lack of study & (ENSG00000008405.11/ENSG00000121671.11) \\
\hline
\end{tabular}

LGG, brain lower grade glioma; GBM, glioblastoma multiforme; PCPG, pheochromocytoma and paraganglioma; HNSC, head and neck squamous cell carcinoma; NPC, nasopharyngeal carcinoma; ACC, adenoid cystic carcinoma; ERK, extracellular signal regulated kinase; MAPK, mitogen activated protein kinase; OSCC, oral squamous cell carcinoma; THYM, thymoma; ESCA, esophageal carcinoma; BRCA, breast invasive carcinoma; Her2, human epidermal growth factor receptor 2; LUAD, lung adenocarcinoma; LUSC, lung squamous cell carcinoma; SARC, sarcoma; YAP1, Yes-associated protein 1; NF- $\kappa B$, nuclear factor- $\kappa B$; PI3K, Phosphatidylinositol-3-kinase; OV, ovarian cancer; CESC, cervical and endocervical cancer; UCEC, uterine corpus endometrium carcinoma; UCS, uterine carcinosarcoma; LIHC, liver hepatocellular carcinoma; PRAD, prostate adenocarcinoma; CHOL, cholangiocarcinoma; KICH, kidney chromophobe; KIRC, kidney renal clear cell carcinoma; KIRP, kidney renal papillary cell carcinoma; EGCG, Epigallocatechin-3-gallate; HCC, hepatocellular carcinoma; BLCA, bladder urothelial carcinoma; STAD, stomach adenocarcinoma EGFR, epidermal growth factor receptor; DPD, dihydropyridine dehydrogenase; TGCT, testicular germ cell tumors; COAD, colon adenocarcinoma; READ, rectum adenocarcinoma; SKCM, skin cutaneous melanoma; AML, acute myeloid leukemia; C/EBPs, CCAAT/enhancer-binding proteins; CML, chronic myeloid leukemia; DLBC, lymphoid neoplasm diffuse large B-cell lymphoma.

\section{Significant Biological activities in Tumor Tissues are Characteristic of Circadian Rhythms}

As a response to the circadian reset of clock genes and the timing of circadian rhythms, the circadian clocks of tumor tissues and their cellular behaviors a differ from those of normal tissues.

The proliferation rhythms in tumor cells also differ from those of normal cells. For bone marrow cells, the highest proliferation rate peaks from the second half of the night to early in the morning, while tumor cells proliferate most actively during the first half of the night. Circadian variations in cell proliferation result from the synchronous progression of cell cycle events. The oscillation of platelet-derived growth factor (PDGF) signaling could modulate the expression of cell cycle regulators and then lead to the transition of quiescent cells into the proliferative stage (Nakagawa et al., 2008). As a result, analysis of cell-cycle distribution in malignant tissues may offer beneficial information for many chemotherapeutic agents based on phase-specificity. For example, the application of antimitotic drugs at a suitable time point can target G2/M gating of the cell cycle, which is regulated by resetting the circadian rhythm in malignant tumors. And studies show that the proliferation gene Ki-67 is regulated by the clock genes. In tumors, the circadian reset of PER1 is related to the increase of Ki-67, accelerating cell proliferation (Ye et al., 2015). In addition, circadian clocks can regulate apoptotic processes. The altered circadian organization of B-cell lymphoma-2 (BCL-2) oncogene, can be considered a regulatory factor of programmed cell death pathways in tumors and serves as a target site for $\gamma$-radiation (Granda et al., 2005). The reset of PERs can inhibit the expression of BCL-2 and modulate tumor apoptosis (Li, 2019).

DNA synthesis in tumor cells results in different circadian rhythm oscillations due to the modulation by AG1295, whose mRNA accumulates nearly at the active period of DNA synthesis (Nakagawa et al., 2008). Telomerase is an important enzyme whose primary function is to maintain 

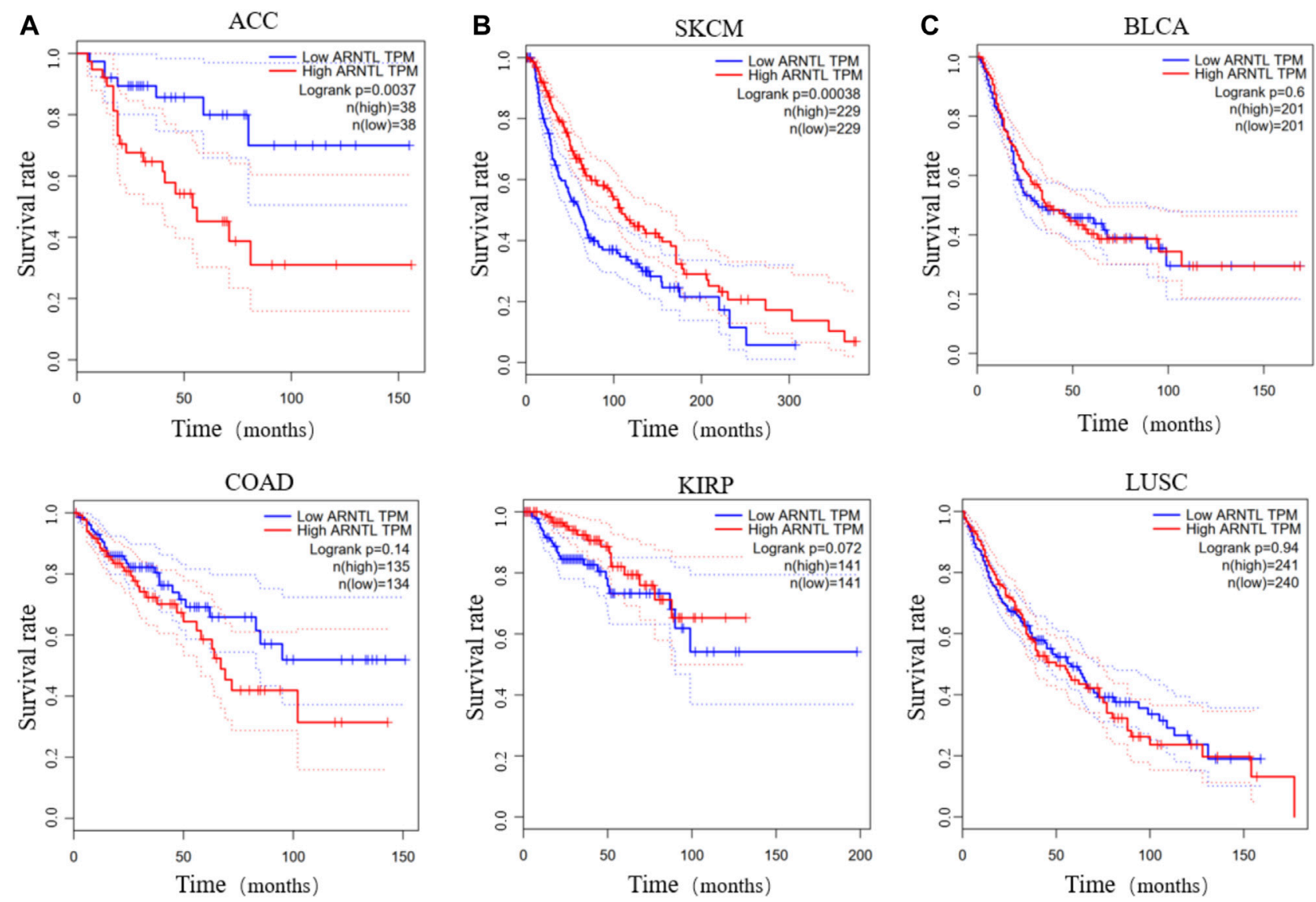

FIGURE 2 The survival rate of low and high BMAL1 TPM in different cancers. Low BMAL1 TPM relates to a high overall survival rate in patients with ACC or COAD (A). High BMAL1 TPM relates to a high overall survival in SKCM or KIRP (B). The expression of BMAL1 is irrelevant in BLCA or LUSC (C).

the correct length of the telomere. In normal organisms, there is a balance between the activity of telomerase and cell replication. Circadian clocks regulate telomerase expression, escaping damage through cellular replicative senescence to ensure cell eternity in tumor cells when circadian clocks have changed (Sulli et al., 2019). In addition, the response to DNA damage is activated in cells every day, and the level of expression of the pivotal circadian clock gene PER1 is largely involved in DNA repair. PER1 contribute to G1/S and G2/M arrest by the Cyclin-cyclin-dependent kinase (CDK) inhibitor regulatory network (Fu et al., 2016). CLOCK can regulate the rhythmic profile of p53 and reset DNA damage. Thus, when the core negative regulators are down-regulated, the proper cellular response to DNA damage is disturbed (Wang et al., 2016). Further, the response of tumor cells to DNA damage differs from that of normal tissues (Sulli et al., 2019). Consequently, differences in DNA behavior due to the resetting of the circadian genes is responsible for the antimetabolic activity of drugs used in cancer chronotherapies.

When a malignancy arises, homeostatic mechanisms are dysregulated, as the energy needs of cancer cells are altered or even increased. Tumor cells reprogram their metabolism to ensure a steady supply of metabolites to generate new biomass. Therefore, these changes can be correlated with an increase in aerobic glycolysis and lipogenesis. Increased glycolysis and lipogenesis are responsible for fatty acid oxidation and methionine synthesis pathways, and both processes show circadian rhythms. In AML, UDP-glucose (Uridine diphosphate-glucose), a glycogenic precursor, is persistently upregulated. Patients with chronic lymphocytic leukemia (CLL) show high circulating levels of pyruvate and glutamate in their blood (Padmanabhan and Billaud, 2017). Based on Fuhr et al.'s research, genes involved in glycolysis and oxidative phosphorylation pathways oscillate between peak values in colorectal cancer cell lines. The oscillatory oxygen consumption rates (OCRs) show an ultradian pattern because the peak in downstream proteins present an 18-h phase shift compared to normal cells. Through unknown mechanisms synchronization occurs later, and viability and cytotoxicity decrease in the cells (Fuhr et al., 2018). KMT2D enhances Per2 expression through superenhancer activation and it inhibits glycolytic genes via IGFBP5-regulated insulin-like growth factor (IGF) signaling. Targeting KMT2D may contribute to rationalize glycolysis inhibition as an anticancer treatment strategy (Alam et al., 2020). 


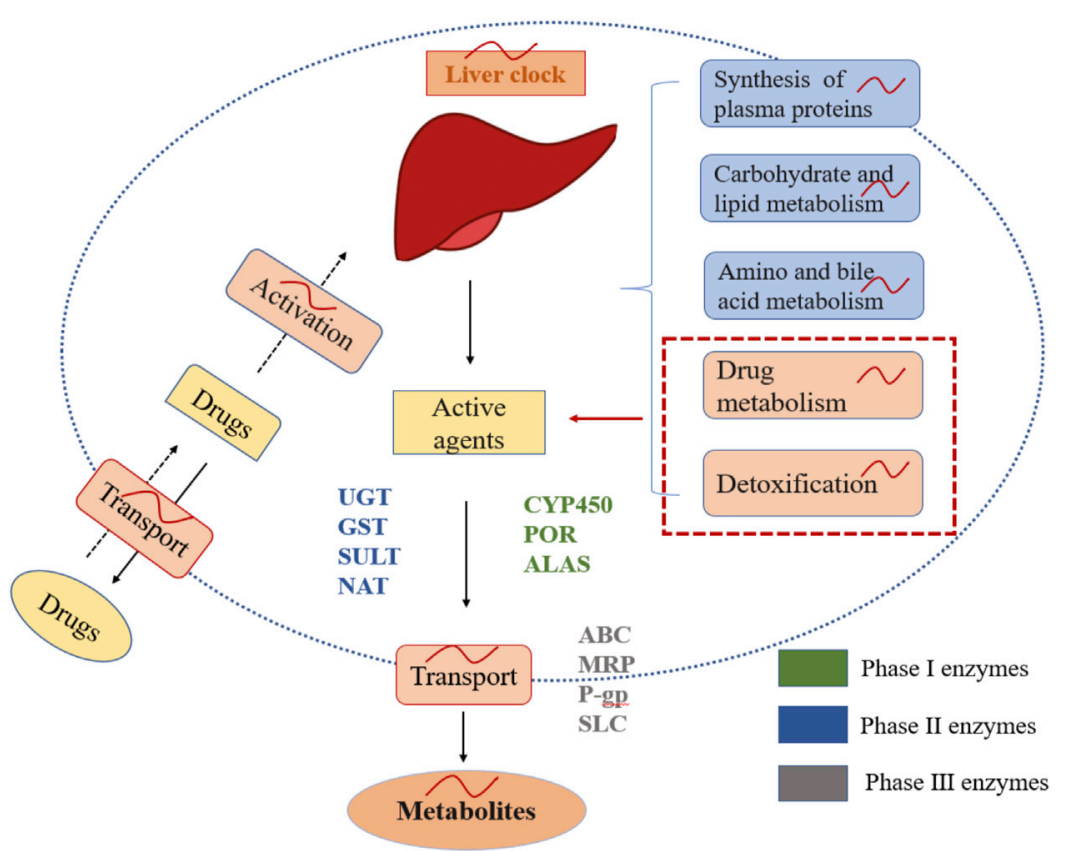

FIGURE 3 | Chrono-pharmacokinetics of drug metabolism, detoxification, and delivery with metabolizing enzymes in the liver. The liver is controlled by circadian clocks that account for chrono-pharmacokinetics. Drug metabolism, detoxification, and delivery with metabolizing enzyme families are rhythmic in the liver.

The biological behaviors of tumor cells transform to reset their circadian rhythms compared with normal cells, including cell proliferation and differentiation, DNA synthesis and replication, and metabolic activities. These processes are of great concern for the tumor process. These differences in circadian rhythms are also the biological basis of chronotherapies of cancers.

\section{CANCER CHRONOTHERAPIES}

The CTS comprises molecular clocks, driving 24-h fluctuations in detoxification and xenobiotic metabolism, immune functions, cellular proliferation, angiogenesis, apoptosis, cell cycle events, DNA repair, and many signal transduction pathways. The CTS controls drug absorption, distribution, metabolism, and excretion (ADME), which influence the chronopharmacokinetics of anticancer agents controlled by rhythmic physiology and circadian clock signaling. Conversely, the CTS also regulates cell cycle events, molecular targets, signal channels, DNA repair, and apoptosis. The CTS is responsible for the chronopharmacodynamics of anticancer drugs, radiotherapy, and other treatments with clock genes at the molecular level. The relationships between chronopharmacokinetics and chronopharmacodynamics can be used to construct optimal chronomodulated drug delivery schedules (Ozturk et al., 2017). Those cellular or pharmacologic determinants form the therapeutic potential of circadian-based chronotherapies against cancers. Essentially, chronotherapies improve the efficacy and tolerability of anticancer drugs.

\section{Chronopharmacokinetics of Chronotherapies}

Drug pharmacokinetics govern ADME properties from the cellular to systemic levels with circadian rhythms. The ADME properties of anticancer drugs are at the mercy of large circadian variations (Levi and Schibler, 2007), such as rest-activity patterns, which could modulate blood pressure and flow to change drug absorption, cooperating with gastric $\mathrm{pH}$ and gastrointestinal motility (Cederroth et al., 2019). The elimination of drugs in the urine are related to several intrinsic renal variables, including glomerular filtration rate (GFR), the renal blood flow (RBF), and alkalinization/acidification degree of urine in the kidney (urine $\mathrm{pH}$ ). Elimination mechanisms also follow the circadian rhythm of metabolic enzymes (Gachon and Firsov, 2011). Some agents that regulate gastrointestinal motility and renal variables can influence drug pharmacokinetics. For instance, brain-derived neurotrophic factor (BDNF) induces the contractility of smooth muscle cells (SMCs) by tyrosine kinase receptor B (TrkB)/RhoA/ROCK signaling. In addition, $\mathrm{BDNF}$ also augments noradrenergic noncholinergic (NANC) relaxation via the nitric oxide (NO)/ soluble guanylate cyclase (sGC) pathway (Singh et al., 2020; Singh et al., 2021).

Circadian rhythms of drug metabolism, detoxification, and drug transport are closely associated with drug-metabolizing enzyme families (Figure 3). Phase I and II drug-metabolizing enzyme families contain cytochrome P-450 (CYP450), aminolaevulinic acid synthase (ALAS), P450 oxidoreductase (POR), UDP-glucuronosyl transferase (UGT), glutathione-Stransferase (GST), N-acetyl transferase (NAT), and sulfotransferase (SULT). They play critical roles in oxidation, 
reduction, hydrolysis, and conjugation reactions (Gachon and Firsov, 2011). CYP450 catalyzes oxidative biotransformation in numerous drugs, and account for approximately $\sim 75 \%$ of their overall metabolism (Zanger and Schwab, 2013). All these enzymes are regulated by clock genes such as CLOCK and $B M A L 1$, and by the circadian clock-regulated PAR-domain basic leucine zipper (RARbZip) transcription factor family (Gachon et al., 2006; Kang et al., 2007; Zhang et al., 2009; Tanimura et al., 2011). In addition, these enzyme families participate in hepatic metabolism, the liver being the primary organ of drug metabolism and detoxification and is characterized by its capacity of producing its circadian rhythms (Turek and Allada, 2002). Studies have also shown that the circadian clocks control Cyp2a5, Cyp2b10, and Cyp3a11 mRNA levels in the liver or intestinal tract of mice. Cyp4a isoforms in the liver modulate renal function by catalyzing the formation of 20hydroxyeicosatetraenoic acid, efficiently influencing tubular ion transport and renal vasculature, which might explain the circadian rhythms of blood pressure and renal function (Ohdo et al., 2019). The glutathione content in the liver is possibly higher in the second half of the dark span of the light-dark cycle. Suppressing the synthesis of glutathione could alter the chrono-tolerance patterns of oxaliplatin and cisplatin. In contract, UGT contents are higher during the dark span in mice. It relates to the chrono-tolerance of seliciclib and irinotecan. Phase III metabolizing enzyme families consist of ATP-Binding Cassette (ABC) transporters, including P-glycoprotein (P-gp), multi-drug resistance-associated proteins (MRP), and solute carrier (SLC) superfamily. These enzymes are responsible for transporting drugs in to and out of target tissues and cells (Gachon and Firsov, 2011). The expressions of $\mathrm{ABC}$ and SLC transporters are rhythmic in the liver and the intestine of mice. The ABCB1a and ABCB1b mRNA rhythms further increase the activity of $\mathrm{P}$-gp during the dark span in mice. In short, changes in circadian rhythms in multifold enzymes and transporter function can potentially lead to 24-h changes in ADME properties of anticancer drugs and then lead to differences in daily bioavailability of drugs between organisms. Furthermore, changing or identifying the optimal time for the expression of specific enzymes or transporters may improve the tolerability and curative effects of anticancer drugs.

\section{Chrono-Pharmacodynamics of Chronotherapies}

Drug activities are mainly under the control of the CTS at the molecular level, with several molecular drug targets involved in several biological functions, including cell cycle events, DNA repair, angiogenesis, intracellular targets, and triggered pathways (Singh et al., 2016; Ballesta et al., 2017). Circadian clocks mediate cell cycle events that cooperate with clock genes and signaling pathways in oncogenesis, either transcriptionally or via protein-protein interactions. Studies show that BMAL1 inhibit cyclin E transcription to block the formation of the Cyclin E/CDK (cyclin-dependent kinase) complex, leading to cell cycle arrest in G1/S. Wee1 inactivates the CDK1/CycB complex by phosphorylation to eliminate inhibition of $\mathrm{pCDK} 1$ to improve
G2/M phase transition (Soták et al., 2014). Dallmann et al. also demonstrated that DNA synthesis in the $\mathrm{S}$ phase and mitosis rhythms occur in hematopoietic cells, immune system cells, and gastrointestinal tract cells. This process targets cancer-related signal transduction pathways such as epidermal growth factor receptor (EGFR) and Rat sarcoma/rapidly accelerated fibrosarcoma/mitogen-activated protein kinase (Ras/Raf/ MAPK). Furthermore, drugs targeting tubulin and microtubule in the G2/M phase are also implicated in different chronotherapy approaches. Kumar et al. showed that modulation of tubulinmicrotubule dynamics interacts with vascular endothelial growth factor (VEGF) and hypoxia inducible factor- $\alpha$ (HIF- $\alpha$ ) to reduce mice mammary carcinoma volumes by $48.2 \%$ (Srivastava et al., 2020). In addition, the clock genes could also be involved in apoptosis by modulating signaling pathways. BMAL1 can suppress the expression of p21 indirectly via the retinoic acidassociated orphan receptor a (RORa) pathway (Kelleher et al., 2014). Methionine aminopeptidase 2 (MetAP2) positively regulates endothelial cell proliferation during tumor angiogenesis. The CLOCK/BMAL1 heterodimer in the clock feedback loop enhances the transcription of the MetAP2 promoter, while PER2/CRY1 inhibits promoter activation (Nakagawa et al., 2004). Furthermore, clock genes can regulate DNA repair and damage. Increasing DNA damage and genome instability has been observed in Cry2-deleted cells, suggesting a specific role for Cry in the transcriptional regulation of DNA repair. Furthermore, CRY activates the ATM and Rad3-related/ creatine phosphokinase1 (ATR/CHK1) signaling pathways of DNA damage with Timeless protein (TIM), and PER1 also plays a significant role in the Ataxia telangiectasia mutated creatine phosphokinase2 (ATM-CHK2) protein complex to activate the DNA double-strand break process. All of the above biological functions can be considered molecular targets of anticancer drugs able to suppress the cancer process. Due to the regulation of circadian rhythms, it is possible to reduce side effects and improve efficacy by administering drug treatments that are optimally timed and using the proper doses. In short, chronopharmacokinetic and chronopharmacodynamics constitute an area of chronopharmacology providing a mechanistic rationale to successful treatment outcomes.

\section{Chrono-Chemotherapy, Targeted Therapy, and Radiotherapy Applications}

Chemotherapy is one of treatment approach for tumors. To date, studies have observed the correlation between chronotherapies and chemotherapy and have identified relevant chemotherapy drugs for chronochemotherapy. Okazaki et al. used tumorbearing mice as a model and determined that the survival rate of mice was higher when treatment was administered everolimus at 7:00 p.m. rather than at 7:00 a.m. (Okazaki et al., 2014). Another study showed that the antitumor effect of interferon (IFN)- $\beta$ in nocturnally active mice was more efficient during the early rest phase than during the early activation phase (Takane et al., 2000). Imatinib is an antitumor agent that suppresses the activity of multifarious receptors with tyrosine kinase activity, also known as a protein receptor tyrosine kinase inhibitor (PKTI). 
Imatinib mesylate $(50 \mathrm{mg} / \mathrm{kg})$ administered during the early light phase reduces tumor growth (Nakagawa et al., 2006). Furthermore, many other anticancer drugs in which administration in line with the timing of the circadian improves antitumor efficacy have been reported, including antimetabolites (e.g., 5-fluorouracil, 1-alanosine, gemcitabine, floxuridine) (Li et al., 2006; Li et al., 2005; von Roemeling and Hrushesky, 1990; Wood et al., 2006); topoisomerase I inhibitors (e.g., irinotecan, topotecan, and 9-aminocamptothecin) (Kirichenko and Rich, 1999; Granda et al., 2002; Mullins et al., 2005); topoisomerase II inhibitors (etoposide) (Lévi et al., 1985); alkylators (e.g., oxaliplatin, cyclophosphamide, melphalan, carboplatin, and nedaplatin) (Halberg et al., 1980; Scheving et al., 1980; Boughattas et al., 1990; Granda et al., 2002; Cui et al., 2004); cytokines (e.g., INF- $\alpha$, INF- $\gamma$, INF- $\beta$, interleukin-2, BDNF) (Kemeny et al., 1992; Takane et al., 2000; Shinohara et al., 2008; Singh et al., 2021); hormones (e.g.tamoxifen) (Binkhorst et al., 2015), mitotic inhibitors e.g., docetaxel and vinorelbine (Filipski et al., 1999; Granda et al., 2001), DNA intercalators (e.g. doxorubicin) (To et al., 2003), cell cycle inhibitors (e.g. seliciclib, paclitaxel, diosgenin derivatives, analogues of 2-methoxyestradiol (2ME2), neolignans 10, and curcumin mimic 6a) (Iurisci et al., 2006; Sathish Kumar et al., 2014a; Sathish Kumar et al., 2014b; Hamid et al., 2014; Tang et al., 2017; Khwaja et al., 2018); cyclooxygenase or COX-2 inhibitors (e.g., celecoxib) (Blumenthal et al., 2001); and VEGF inhibitor (e.g., TNP-470 or O-(chloroacetyl-carbamoyl) fumagillol)), the matrix metalloproteinase inhibitor BB2516), and the VEGFR-2 TKI SU1498 (Koyanagi et al., 2003a; Koyanagi et al., 2003b). Generally speaking, cancer chronotherapies consider the association of anticancer drugs with treatment in line with a patient's circadian rhythm. Therefore, studying the rhythmicity of these drugs provides enhanced treatments for cancers.

Targeted therapy of tumors aims at recognizing specific antigens on the surface of tumor cells through monoclonal antibodies. Conversely, it also aims at suppressing tumor cell growth through small molecules that block intracellular signal transduction by tyrosine kinases. These intracellular signals include extracellular signal-regulated kinase/mitogen-activated protein kinase (ERK/MAPK), Janus kinase (JAK), PI3K, estrogen receptor (ER), and EGFR (Firer and Gellerman, 2012). Targeted therapy has also observed circadian rhythms. Lapatinib proves to be a clock-targeted drug inhibitor of EGFR in breast cancer, acting on everolimus. Everolimus is an inhibitor of the Mammalian target of rapamycin (mTOR) through the EGFR/ Ras/Ras/MAPK pathway (Pagani et al., 2011; Azzi et al., 2014; Zappe et al., 2015). Besides, lapatinib also improves the survival rate of cancer patients when administered in patients overexpressing mTOR (Okazaki et al., 2014). Other chronotarget drugs, such as erlotinib, as the EGFR inhibitor for lung cancer, have also already been reported. Erlotinib displays anti-tumor activities more effectively on tumor growth inhibition when administered in the early-light than in the early-dark phase of the circadian rhythm when EGFR activities and its downstream factors increase (Li XM. et al., 2013; Lin et al., 2015). Benzylidene indanone 1 induces apoptosis in DU145 cells by cleavage of poly ADP-ribose polymerase
(PARP) (Singh et al., 2015). Hamid et al. determined that diosgenin and related compounds induce apoptosis in DU145 prostate cancer cells through the caspase pathway (Hamid et al., 2017). Targeted therapy for specific cancer sites is based on selective and available properties of cancers and normal cells with the context of the circadian clocks.

Similarly, radiation therapy is also associated with circadian rhythms influencing the expression of clock genes such as $B M A L 1, C L O C K, P E R$, and CRY. The clock genes coordinate molecular events and generate circadian rhythms influencing radiotherapy throughout the 24 -h period. It predisposes cells to be more sensitive to treatments at a specific period (Palombo et al., 2015). Chronological exposure to radiation and DNA damaging agents, such as temozolomide, has an significant impact on the survival of brain tumor cells in culture (Stupp et al., 2005). Other studies also show that chrono-modulated radiation, either alone or with other drugs, can be responsible for improving therapeutic efficacy (Akgun et al., 2014). However, chrono-radiotherapy may also cause various side effects, such as long-lasting sleep disruption, cognitive defects, hair loss, and dermatitis. Therefore, the current attention to chrono-modulated administration of radiation has addressed how to reduce treatment-related symptoms. A study published by Noh et al. treated 395 patients with radiotherapy in the early morning and early evening and found that the early evening-treated group experienced significantly higher acute skin reactions compared to the morning treated group (Noh et al., 2014). Other studies demonstrated that exposure to radiation, resulted in greater hair loss in the morning and that Xpa levels were lower compared to those in the evening. These results indicate that studying the side effects of radiation chronotherapy to improve the therapeutic efficacies in tumor cells is warranted.

An increasing number of treatments support the therapeutic utility of circadian rhythms in cancer treatment This approach focuses on optimizing drug tolerability and efficacy and improving quality of life in cancer patients (Table 2).

\section{Combination of Clinical Chronotherapy Schedules}

In particular, chronotherapy aims to maximize antitumor effects and to minimize the toxicity of anticancer agents in normal tissues. Patients who received chrono-modulated infusions of 5FU, leucovorin, and oxaliplatin at separate times showed a low frequency of side effects (Lévi et al., 1992; von Roemeling and Hrushesky, 1989). In their study, Levi et al. compared the efficacy of chrono-modulated infusion to the standard fixed infusion. Patients received the 5-FU chrono-modulated infusion with administration maximum at 4:00 a.m. and the oxaliplatin administration time was maximum at 16:00. This three-drug chronomodulated regimen (chrono-FFL) produced a $58 \%$ response rate in 93 patients with metastatic colorectal cancer (Lévi et al., 1995). Taking Capecitabine 50\% dose at 8:00 a.m. and $50 \%$ dose at midnight with radiotherapy decreases the toxicity of hand-foot syndrome, thrombocytopenia, diarrhea, and mucositis. Subsequently, the median survival rate was also prolonged (Akgun et al., 2014). Cisplatin often combinates with 
TABLE 2 | The correlation between anticancer drugs and circadian rhythmicity from studies.

\begin{tabular}{|c|c|c|c|c|c|}
\hline Classification & Drugs & Cancer types & Schedule & Evidence & References \\
\hline \multirow[t]{5}{*}{ Antimetabolite } & 5-fluorouracil & Colon cancers & at 4:00 a.m. & Meta-analysis & Wood et al. (2006) \\
\hline & L-alanosine & Lymphocytic leukemia & the half of the activity span & Animal study & Li et al. (2006) \\
\hline & Gemcitabine & Osteosarcoma & 3-day interval & Animal study & Li et al. (2005) \\
\hline & Floxuridine & Breast cancer & the late activity-early rest span & Animal study & $\begin{array}{l}\text { von Roemeling and Hrushesky, } \\
\text { (1990) }\end{array}$ \\
\hline & Capecitabine & Rectal cancer & at 8:00 a.m.\&12:00p.m. & Phase II study & Akgun et al. (2014) \\
\hline \multirow[t]{3}{*}{ Top I inhibitor } & Irinotecan & Colorectal cancer & at 5:00 a.m. & PK study & Granda et al. (2002) \\
\hline & Topotecan & Breast cancer & at 3:00 a.m. & Animal study & Mullins et al. (2005) \\
\hline & $9-A C$ & Breast cancer & the rest phase & Animal study & Kirichenko and Rich, (1999) \\
\hline mTOR inhibitor & Everolimus & Renal cell carcinoma & at 19:00 p.m. & Animal study & Okazaki et al. (2014) \\
\hline \multirow[t]{2}{*}{ PKTI } & Imatinib & Sarcoma/Melanoma & the early light phase & Animal study & Nakagawa et al. (2006) \\
\hline & Lapatinib & Sarcoma/Melanoma & high expression of mTOR & Animal study & \\
\hline \multirow[t]{3}{*}{ Cytokines } & Interferon a & Melanoma & at $12: 00$ a.m. to $04: 00$ a.m. & Animal study & Takane et al. (2000) \\
\hline & Interferon $\gamma$ & Melanoma & at $16: 00$ p.m. & Animal study & Takane et al. (2000) \\
\hline & Interleukin-2 & Hepatoma & day cycle & Animal study & Kemeny et al. (1992) \\
\hline \multirow[t]{4}{*}{ Alkylator } & Cisplatin & NSCLS & at 6:00 a.m. \& 18:00 p.m. & $\begin{array}{l}\text { Randomized controlled } \\
\text { study }\end{array}$ & Boughattas et al. (1990) \\
\hline & Oxaliplatin & Colon cancer & at $16: 00$ p.m. & Animal study & Granda et al. (2002) \\
\hline & CTX & Leukemia & at $11: 00$ a.m. & Animal study & Scheving et al. (1980) \\
\hline & Carboplatin & NSCLS & at $20: 00$ p.m. & Toxicity analysis & Boughattas et al. (1990) \\
\hline Hormones & Tamoxifen & Breast cancer & at 8:00 a.m. /13:00 p.m. /20:00 p.m. & Animal/clinical study & Binkhorst et al. (2015) \\
\hline DNA intercalator & Doxorubicin & Adenocarcinoma & middle of the rest span & Animal study & To et al. (2003) \\
\hline \multirow[t]{2}{*}{ Mitotic inhibitor } & Docetaxel & Adenocarcinoma & middle of the rest span & Animal study & Granda et al. (2001) \\
\hline & Vinorelbine & Leukemia & & Animal study & Filipski et al. (1999) \\
\hline \multirow[t]{2}{*}{ Cell cycle inhibitor } & Seliciclib & Osteosarcoma & the early light phase & Animal study & lurisci et al. (2006) \\
\hline & Paclitaxel & TSCC & BMAL1 overexpression & Cell study & Tang et al. (2017) \\
\hline Cox-2 inhibitor & Celecoxib & Breast cancer & at 5:00 a.m. to $1: 00$ p.m. & Animal study & Blumenthal et al. (2001) \\
\hline \multirow[t]{2}{*}{ VEGF inhibitor } & SU1498 & Lung carcinoma & early of the rest span & Animal study & Koyanagi et al. (2003a) \\
\hline & BB2516 & Lung carcinoma & early of the rest span & Animal study & \\
\hline Radiation & $\gamma$-radiation & Rectal cancer & at 8:00 a.m.\&12:00p.m. & Phase II study & Akgun et al. (2014) \\
\hline
\end{tabular}

9-AC, 9-aminocamptothecin; NSCLC, non-small cell lung cancer; CTX, cyclophosphamide; TSCC, tongue squamous cell carcinoma; Cox-2, cyclooxygenase-2; BB2516, matrix metalloproteinase inhibitor; SU1498, VEGFR-2, tyrosine kinase inhibitor.

doxorubicin. Patients with ovarian or bladder cancer in a phase-II trial confirmed the better tolerability of morning doxorubicin and evening cisplatin (Innominato et al., 2010). The improvements of chrono-tolerability reduce toxicity or sideeffects with conventional schedules. Chronomodulated delivery, therefore, enables the therapeutic efficacy to increase.

\section{PERSONALIZED BIOMARKERS FOR PRECISION CHRONOTHERAPIES \\ Temperature, Rest-Activity, and Some Hormones are Biomarkers}

The SCN, a main circadian oscillator of the CTS, produces behavioral rhythms and synchronizes clocks in peripheral organs, causing measurable and therapeutically available circadian oscillations. Therefore, the rhythms of body temperature, hormone secretion, autonomic nervous system activity, cytokine release, and resting-activity form a dynamic physiological network that interacts with peripheral clocks. These rhythms serve as biomarkers of the CTS to optimize precise chronotherapy timing and dosing in individual cancer patients, respectively. Temperature forms a biomarker for cancer chemotherapy (Lévi et al., 2010). The monitoring of skin surface temperature could provide supplementary information regarding circadian phase and the CTS robustness. Patients maintain robust circadian rhythms with consistent 24-h temperature amplitudes and resting-activity after chronotherapy due to drug delivery patterns that involve administration at proper times and anti-cancer drug dose. However, chronotherapy may induce a transient or continuous circadian disturbance in the other patients, may due to the poor timing of the single or fixed chronotherapy protocols during the internal phases of those patients, which can reduce the antitumor efficacy and tolerability of anticancer therapies (Roche et al., 2014). In other clinical trials, cervical and lung cancer patients were randomly divided into several groups and received the same radiotherapy but with varying body temperatures. The growth of tumor cells was inhibited when radiotherapy was applied at the peak of body temperature. In general, resting-activity, body temperature, saliva cortisol levels, plasma catecholamines, and melatonin levels, among the various circadian biomarkers, show statistically significant and consistent rhythms in patients with early or advanced colon, lung, ovary, breast, prostate, or head and neck cancers (Lévi et al., 2010). Measurement of these biomarker patterns could help to deliver CTS information on robustness, synchronization, and internal clock timing. Confirming the peak or trough in these patterns can identify the optimal internal timing for chronotherapy delivery in individual patients. 


\section{BMAL1 and PER Serve as Biomarkers}

At the molecular level, some transcription-translation feedback loops with self-regulating functions also maintain the stability of circadian rhythms. The central feedback loop consists mainly of clock genes, such as BMAL1, CLOCK, and downstream genes, including PER and CRY (Panda et al., 2002). Clock genes affect physiological functions of the whole body in tissues and cells specifically through multiple signal pathways, which account for interindividual differences in relevant circadian rhythms. BMAL1 is an important transcription factor in this feedback loop that may suppress the growth, proliferation, and proliferation of multiple cancer cells, including tongue squamous cancer cells, colorectal cancer cells, breast cancer cells, and ovarian cancer cells (Gréchez-Cassiau et al., 2008; Hanahan and Weinberg, 2011; Elshazley et al., 2012; Hsu et al., 2012). Furthermore, BMAL1 expression influences the sensitivity of chemotherapeutic drugs, including irinotecan (Dulong et al., 2015), oxaliplatin (Zeng et al., 2014), PTX (Tang et al., 2017), and cyclophosphamide. According to studies, BMAL1 acts directly on DNA telomeres to recruit EZH2 for combining with TERT promoter to negatively regulate TERT transcription and increase TERT expression, which leads to the improvement of PTX sensitivity of TSCC. Furthermore, the efficacy of PTX in TSCC is highly consistent with the expression of BMAL1. The higher expression of BMAL1, the better the efficacy of PTX. In addition, since BMAL1 expression exhibits a stable circadian rhythm in healthy individuals and in cancer cells, BMAL1 could serve as a direct molecular target for PTX to determine the best drug administration time for personalized chronotherapies (Tang et al., 2017) and may contribute to improving the efficacy of anticancer drugs and reduce their toxicity.

Besides BMAL1, period genes (PER1 and PER2) as clock genes having expression synchronized with steady circadian rhythms also influence the progression of tumors. The expression of these genes decrease in patients with pancreatic carcinoma (Relles et al., 2013), head and neck neoplasm (Hsu et al., 2012), or breast cancer (Winter et al., 2007). Niu et al. used an animal model of brain glioma to study the expressions of Per1 and Per2 in normal and glioma tissues, and determined that the expression of Per 1 was at its minimum at midnight, while the expression of Per2 is maximal at midnight and minimum at 8:00 a.m. in glioma tissues (Zhanfeng et al., 2015). Another study treated animals with radiotherapy at different time points based on the disparate expression of Per1 or Per2 (Zhanfeng et al., 2015). The results showed that the apoptosis rate of glioma cells was higher when radiotherapy was administered at the peak of Per1 or Per2

\section{REFERENCES}

Akgun, Z., Saglam, S., Yucel, S., Gural, Z., Balik, E., Cipe, G., et al. (2014). Neoadjuvant Chronomodulated Capecitabine with Radiotherapy in Rectal Cancer: a Phase II Brunch Regimen Study. Cancer Chemother. Pharmacol. 74, 751-756. doi:10.1007/s00280-014-2558-x

Alam, H., Tang, M., Maitituoheti, M., Dhar, S. S., Kumar, M., Han, C. Y., et al. (2020). KMT2D Deficiency Impairs Super-enhancers to Confer a Glycolytic Vulnerability in Lung Cancer. Cancer cell 37, 599-e7. e597. doi:10.1016/ j.ccell.2020.03.005 expression, indicating that clock genes could act as molecular targets that regulate chronotherapy efficacy and promote personalized therapeutic effects.

Precise biomarkers or targets with constant rhythms in individuals can help identify personalized circadian rhythms in order to optimize treatment plans and thus, maximize treatment efficacy and improve quality of life.

\section{CONCLUSION AND FUTURE PROSPECTS}

Biological clocks are closely associated with the occurrence and development of tumors. Chronotherapies that exploit circadian rhythms in experimental and preclinical trials are based on the development of therapeutic interventions that consider the influence of treatment mechanisms of action and the circadian status of the tumor targets. More importantly, personalized precision chronotherapies combined with biomarkers can optimize the effective management of the administration of the chronotherapy, in clinical trials and ultimately in individual care in cancer patients. The personalized precision chronotherapy approach is characterized by the maximum therapeutic effect achievable, minimum side effects, and relatively higher potential risk prediction. Further studies should identify other biomarkers able to ameliorate personalized chronotherapies, and to provide precise chronotherapy strategies. In addition, a neoteric approach should be developed to exploit drugs that target the circadian clocks to improve efficacy and prognosis.

\section{AUTHOR CONTRIBUTIONS}

JZ and JW performed the original draft preparation, revision, created the tables and figures. And JZ and JW were the major contributors in writing the manuscript. XZ and QT participated in conceptualization and methodology and made suggestions to the writing of the manuscript and revisions to tables and figures. QT supervised the work and acquired funding. All authors read and approved the final manuscript.

\section{FUNDING}

This work was supported by the National Natural Science Foundation of China for Young Scientists (81800986 to QT).

Angelousi, A., Nasiri-Ansari, N., Karapanagioti, A., Kyriakopoulos, G., Aggeli, C., Zografos, G., et al. (2020). Expression of Clock-Related Genes in Benign and Malignant Adrenal Tumors. Endocrine 68, 650-659. doi:10.1007/s12020-02002246-Z

Azzi, A., Dallmann, R., Casserly, A., Rehrauer, H., Patrignani, A., Maier, B., et al. (2014). Circadian Behavior Is Light-Reprogrammed by Plastic DNA Methylation. Nat. Neurosci. 17, 377-382. doi:10.1038/ nn. 3651

Ballesta, A., Innominato, P. F., Dallmann, R., Rand, D. A., and Lévi, F. A. (2017). Systems Chronotherapeutics. Pharmacol. Rev. 69, 161-199. doi:10.1124/ pr.116.013441 
Binkhorst, L., Kloth, J. S. L., de Wit, A. S., de Bruijn, P., Lam, M. H., Chaves, I., et al. (2015). Circadian Variation in Tamoxifen Pharmacokinetics in Mice and Breast Cancer Patients. Breast Cancer Res. Treat. 152, 119-128. doi:10.1007/s10549015-3452-x

Blumenthal, R. D., Waskewich, C., Goldenberg, D. M., Lew, W., Flefleh, C., and Burton, J. (2001). Chronotherapy and Chronotoxicity of the Cyclooxygenase-2 Inhibitor, Celecoxib, in Athymic Mice Bearing Human Breast Cancer Xenografts. Clin. Cancer Res. 7, 3178-3185.

Boughattas, N. A., Lévi, F., Fournier, C., Hecquet, B., Lemaigre, G., Roulon, A., et al. (1990). Stable Circadian Mechanisms of Toxicity of Two Platinum Analogs (Cisplatin and Carboplatin) Despite Repeated Dosages in Mice. J. Pharmacol. Exp. Ther. 255, 672-679.

Cao, Q., Gery, S., Dashti, A., Yin, D., Zhou, Y., Gu, J., et al. (2009). A Role for the Clock Gene Perl in Prostate Cancer. Cancer Res. 69, 7619-7625. doi:10.1158/ 0008-5472.CAN-08-4199

Cederroth, C. R., Albrecht, U., Bass, J., Brown, S. A., Dyhrfjeld-Johnsen, J., Gachon, F., et al. (2019). Medicine in the Fourth Dimension. Cell Metab 30, 238-250. doi:10.1016/j.cmet.2019.06.019

Chen, J., Liu, A., Lin, Z., Wang, B., Chai, X., Chen, S., et al. (2020). Downregulation of the Circadian Rhythm Regulator HLF Promotes Multiple-Organ Distant Metastases in Non-small Cell Lung Cancer through PPAR/NF-kb Signaling. Cancer Lett. 482, 56-71. doi:10.1016/j.canlet.2020.04.007

Chen, Z., Liu, P., Li, C., Luo, Y., Chen, I., Liang, W., et al. (2013). Deregulated Expression of the Clock Genes in Gliomas. Technol. Cancer Res. Treat. 12, 91-97. doi:10.7785/tcrt.2012.500250

Cui, Y., Sugimoto, K., Kawai, Y., Sudoh, T., Gemba, M., and Fujimura, A. (2004). Chronotoxicity of Nedaplatin in Rats. Chronobiol Int. 21, 601-611. doi:10.1081/ cbi-120039814

de Assis, L. V. M., Kinker, G. S., Moraes, M. N., Markus, R. P., Fernandes, P. A., and Castrucci, A. M. L. (2018). Expression of the Circadian Clock Gene BMAL1 Positively Correlates with Antitumor Immunity and Patient Survival in Metastatic Melanoma. Front. Oncol. 8, 185. doi:10.3389/fonc.2018.00185

Dulong, S., Ballesta, A., Okyar, A., and Lévi, F. (2015). Identification of Circadian Determinants of Cancer Chronotherapy through In Vitro Chronopharmacology and Mathematical Modeling. Mol. Cancer Ther. 14, 2154-2164. doi:10.1158/1535-7163.MCT-15-0129

Elshazley, M., Sato, M., Hase, T., Yamashita, R., Yoshida, K., Toyokuni, S., et al. (2012). The Circadian Clock Gene BMAL1 Is a Novel Therapeutic Target for Malignant Pleural Mesothelioma. Int. J. Cancer 131, 2820-2831. doi:10.1002/ ijc. 27598

Filipski, E., Amat, S., Lemaigre, G., Vincenti, M., Breillout, F., and Lévi, F. A. (1999). Relationship between Circadian Rhythm of Vinorelbine Toxicity and Efficacy in P388-Bearing Mice. J. Pharmacol. Exp. Ther. 289, 231-235.

Firer, M. A., and Gellerman, G. (2012). Targeted Drug Delivery for Cancer Therapy: the Other Side of Antibodies. J. Hematol. Oncol. 5, 70. doi:10.1186/1756-8722-5-70

Fu, X. J., Li, H. X., Yang, K., Chen, D., and Tang, H. (2016). The Important Tumor Suppressor Role of PER1 in Regulating the Cyclin-CDK-CKI Network in SCC15 Human Oral Squamous Cell Carcinoma Cells. Onco Targets Ther. 9, 2237-2245. doi:10.2147/OTT.S100952

Fuhr, L., El-Athman, R., Scrima, R., Cela, O., Carbone, A., Knoop, H., et al. (2018). The Circadian Clock Regulates Metabolic Phenotype Rewiring via HKDC1 and Modulates Tumor Progression and Drug Response in Colorectal Cancer. EBioMedicine 33, 105-121. doi:10.1016/j.ebiom.2018.07.002

Gachon, F., and Firsov, D. (2011). The Role of Circadian Timing System on Drug Metabolism and Detoxification. Expert Opin. Drug Metab. Toxicol. 7, 147-158. doi:10.1517/17425255.2011.544251

Gachon, F., Olela, F. F., Schaad, O., Descombes, P., and Schibler, U. (2006). The Circadian PAR-Domain Basic Leucine Zipper Transcription Factors DBP, TEF, and HLF Modulate Basal and Inducible Xenobiotic Detoxification. Cel Metab 4, 25-36. doi:10.1016/j.cmet.2006.04.015

Gery, S., Gombart, A. F., Yi, W. S., Koeffler, C., Hofmann, W. K., and Koeffler, H. P. (2005). Transcription Profiling of C/EBP Targets Identifies Per2 as a Gene Implicated in Myeloid Leukemia. Blood 106, 2827-2836. doi:10.1182/blood2005-01-0358

Granda, T. G., D’Attino, R. M., Filipski, E., Vrignaud, P., Garufi, C., Terzoli, E., et al. (2002). Circadian Optimisation of Irinotecan and Oxaliplatin Efficacy in Mice with Glasgow Osteosarcoma. Br. J. Cancer 86, 999-1005. doi:10.1038/ sj.bjc. 6600168

Granda, T. G., Filipski, E., D’Attino, R. M., Vrignaud, P., Anjo, A., Bissery, M. C., et al. (2001). Experimental Chronotherapy of Mouse Mammary Adenocarcinoma MA13/C with Docetaxel and Doxorubicin as Single Agents and in Combination. Cancer Res. 61, 1996-2001.

Granda, T. G., Liu, X. H., Smaaland, R., Cermakian, N., Filipski, E., Sassone-Corsi, P., et al. (2005). Circadian Regulation of Cell Cycle and Apoptosis Proteins in Mouse Bone Marrow and Tumor. FASEB J. 19, 304-306. doi:10.1096/fj.042665fje

Gréchez-Cassiau, A., Rayet, B., Guillaumond, F., Teboul, M., and Delaunay, F. (2008). The Circadian Clock Component BMAL1 Is a Critical Regulator of p21WAF1/CIP1 Expression and Hepatocyte Proliferation. J. Biol. Chem. 283, 4535-4542. doi:10.1074/jbc.M705576200

Gu, D., Li, S., Ben, S., Du, M., Chu, H., Zhang, Z., et al. (2018). Circadian Clock Pathway Genes Associated with Colorectal Cancer Risk and Prognosis. Arch. Toxicol. 92, 2681-2689. doi:10.1007/s00204-018-2251-7

Gutiérrez-Monreal, M. A., Treviño, V., Moreno-Cuevas, J. E., and Scott, S. P. (2016). Identification of Circadian-Related Gene Expression Profiles in Entrained Breast Cancer Cell Lines. Chronobiology Int. 33, 392-405. doi:10.3109/07420528.2016.1152976

Halberg, F., Nelson, W., Levi, F., Culley, D., Bogden, A., and Taylor, D. J. (1980). Chronotherapy of Mammary Cancer in Rats. Int. J. Chronobiol 7, 85-99.

Hamid, A. A., Hasanain, M., Singh, A., Bhukya, B., OmprakashVasudev, P. G., et al. (2014). Synthesis of Novel Anticancer Agents through Opening of Spiroacetal Ring of Diosgenin. Steroids 87, 108-118. doi:10.1016/j.steroids.2014.05.025

Hamid, A. A., Kaushal, T., Ashraf, R., Singh, A., Chand Gupta, A., Prakash, O., et al. (2017). (22 $\beta, 25 \mathrm{R})-3 \beta$-Hydroxy-spirost-5-en-7-iminoxy-heptanoic Acid Exhibits Anti-prostate Cancer Activity through Caspase Pathway. Steroids 119, 43-52. doi:10.1016/j.steroids.2017.01.001

Hanahan, D., and Weinberg, R. A. (2011). Hallmarks of Cancer: the Next Generation. Cell 144, 646-674. doi:10.1016/j.cell.2011.02.013

Hou, L., Li, H., Wang, H., Ma, D., Liu, J., Ma, L., et al. (2020). The Circadian Clock Gene PER2 Enhances Chemotherapeutic Efficacy in Nasopharyngeal Carcinoma when Combined with a Targeted Nanosystem. J. Mater. Chem. B 8, 5336-5350. doi:10.1039/d0tb00595a

Hsu, C. M., Lin, S. F., Lu, C. T., Lin, P. M., and Yang, M. Y. (2012). Altered Expression of Circadian Clock Genes in Head and Neck Squamous Cell Carcinoma. Tumour Biol. 33, 149-155. doi:10.1007/s13277-011-0258-2

Hu, M. L., Yeh, K. T., Lin, P. M., Hsu, C. M., Hsiao, H. H., Liu, Y. C., et al. (2014). Deregulated Expression of Circadian Clock Genes in Gastric Cancer. BMC Gastroenterol. 14, 67. doi:10.1186/1471-230X-14-67

Huang, W., Ramsey, K. M., Marcheva, B., and Bass, J. (2011). Circadian Rhythms, Sleep, and Metabolism. J. Clin. Invest. 121, 2133-2141. doi:10.1172/JCI46043

Innominato, P. F., Lévi, F. A., and Bjarnason, G. A. (2010). Chronotherapy and the Molecular Clock: Clinical Implications in Oncology. Adv. Drug Deliv. Rev. 62, 979-1001. doi:10.1016/j.addr.2010.06.002

Iurisci, I., Filipski, E., Reinhardt, J., Bach, S., Gianella-Borradori, A., Iacobelli, S., et al. (2006). Improved Tumor Control through Circadian Clock Induction by Seliciclib, a Cyclin-dependent Kinase Inhibitor. Cancer Res. 66, 10720-10728. doi:10.1158/0008-5472.CAN-06-2086

Jiang, P., Xu, C., Zhang, P., Ren, J., Mageed, F., Wu, X., et al. (2020). Epigallocatechin-3-gallate I-nhibits S-elf-renewal A-bility of L-ung C-ancer S-tem-like C-ells through I-nhibition of CLOCK. Int. J. Mol. Med. 46, 2216-2224. doi:10.3892/ijmm.2020.4758

Kang, H. S., Angers, M., Beak, J. Y., Wu, X., Gimble, J. M., Wada, T., et al. (2007). Gene Expression Profiling Reveals a Regulatory Role for ROR Alpha and ROR Gamma in Phase I and Phase II Metabolism. Physiol. Genomics 31, 281-294. doi:10.1152/physiolgenomics.00098.2007

Kelleher, F. C., Rao, A., and Maguire, A. (2014). Circadian Molecular Clocks and Cancer. Cancer Lett. 342, 9-18. doi:10.1016/j.canlet.2013.09.040

Kemeny, M. M., Alava, G., and Oliver, J. M. (1992). Improving Responses in Hepatomas with Circadian-Patterned Hepatic Artery Infusions of Recombinant Interleukin-2. J. Immunother. (1991) 12, 219-223. doi:10.1097/ 00002371-199211000-00001

Khwaja, S., Fatima, K., Hasanain, M., Behera, C., Kour, A., Singh, A., et al. (2018). Antiproliferative Efficacy of Curcumin Mimics through Microtubule 
Destabilization. Eur. J. Med. Chem. 151, 51-61. doi:10.1016/ j.ejmech.2018.03.063

Kinouchi, K., and Sassone-Corsi, P. (2020). Metabolic Rivalry: Circadian Homeostasis and Tumorigenesis. Nat. Rev. Cancer 20, 645-661. doi:10.1038/ s41568-020-0291-9

Kirichenko, A. V., and Rich, T. A. (1999). Radiation Enhancement by 9aminocamptothecin: the Effect of Fractionation and Timing of Administration. Int. J. Radiat. Oncol. Biol. Phys. 44, 659-664. doi:10.1016/ s0360-3016(99)00062-0

Koyanagi, S., Kuramoto, Y., Nakagawa, H., Aramaki, H., Ohdo, S., Soeda, S., et al. (2003a). A Molecular Mechanism Regulating Circadian Expression of Vascular Endothelial Growth Factor in Tumor Cells. Cancer Res. 63, 7277-7283.

Koyanagi, S., Nakagawa, H., Kuramoto, Y., Ohdo, S., Soeda, S., and Shimeno, H. (2003b). Optimizing the Dosing Schedule of TNP-470 [O-(chloroacetylcarbamoyl) Fumagillol] Enhances its Antitumor and Antiangiogenic Efficacies. J. Pharmacol. Exp. Ther. 304, 669-674. doi:10.1124/jpet.102.043562

Krugluger, W., Brandstaetter, A., Kállay, E., Schueller, J., Krexner, E., Kriwanek, S., et al. (2007). Regulation of Genes of the Circadian Clock in Human colon Cancer: Reduced Period-1 and Dihydropyrimidine Dehydrogenase Transcription Correlates in High-Grade Tumors. Cancer Res. 67, 7917-7922. doi:10.1158/0008-5472.CAN-07-0133

Lévi, F., Giacchetti, S., Adam, R., Zidani, R., Metzger, G., and Misset, J. L. (1995). Chronomodulation of Chemotherapy against Metastatic Colorectal Cancer. International Organization for Cancer Chronotherapy. Eur. J. Cancer 31a, 1264-1270. doi:10.1016/0959-8049(95)00242-b

Lévi, F., Mechkouri, M., Roulon, A., Bailleul, F., Horvath, C., Reinberg, A., et al. (1985). Circadian Rhythm in Tolerance of Mice for Etoposide. Cancer Treat. Rep. 69, 1443-1445.

Lévi, F., Misset, J. L., Brienza, S., Adam, R., Metzger, G., Itzakhi, M., et al. (1992). A Chronopharmacologic Phase II Clinical Trial with 5-fluorouracil, Folinic Acid, and Oxaliplatin Using an Ambulatory Multichannel Programmable Pump. High Antitumor Effectiveness against Metastatic Colorectal Cancer. Cancer 69, 893-900. cncr2820690410>3.0.co;2-x

Lévi, F., Okyar, A., Dulong, S., Innominato, P. F., and Clairambault, J. (2010). Circadian Timing in Cancer Treatments. Annu. Rev. Pharmacol. Toxicol. 50, 377-421. doi:10.1146/annurev.pharmtox.48.113006.094626

Levi, F., and Schibler, U. (2007). Circadian Rhythms: Mechanisms and Therapeutic Implications. Annu. Rev. Pharmacol. Toxicol. 47, 593-628. doi:10.1146/ annurev.pharmtox.47.120505.105208

Li, A., Lin, X., Tan, X., Yin, B., Han, W., Zhao, J., et al. (2013a). Circadian Gene Clock Contributes to Cell Proliferation and Migration of Glioma and Is Directly Regulated by Tumor-Suppressive miR-124. FEBS Lett. 587, 2455-2460. doi:10.1016/j.febslet.2013.06.018

Li, H. X. (2019). The Role of Circadian Clock Genes in Tumors. Onco Targets Ther. 12, 3645-3660. doi:10.2147/OTT.S203144

Li, S., Qin, X., Chai, S., Qu, C., Wang, X., and Zhang, H. (2016). Modulation of E-Cadherin Expression Promotes Migration Ability of Esophageal Cancer Cells. Sci. Rep. 6, 21713. doi:10.1038/srep21713

Li, X. M., Kanekal, S., Crépin, D., Guettier, C., Carrière, J., Elliott, G., et al. (2006). Circadian Pharmacology of L-Alanosine (SDX-102) in Mice. Mol. Cancer Ther. 5, 337-346. doi:10.1158/1535-7163.MCT-05-0332

Li, X. M., Mohammad-Djafari, A., Dumitru, M., Dulong, S., Filipski, E., SiffroiFernandez, S., et al. (2013b). A Circadian Clock Transcription Model for the Personalization of Cancer Chronotherapy. Cancer Res. 73, 7176-7188. doi:10.1158/0008-5472.CAN-13-1528

Li, X. M., Tanaka, K., Sun, J., Filipski, E., Kayitalire, L., Focan, C., et al. (2005). Preclinical Relevance of Dosing Time for the Therapeutic index of Gemcitabine-Cisplatin. Br. J. Cancer 92, 1684-1689. doi:10.1038/sj.bjc.6602564

Li, Y., Basti, A., Yalçin, M., and Relógio, A. (2020). Circadian Dysregulation of the TGFß/SMAD4 Pathway Modulates Metastatic Properties and Cell Fate Decisions in Pancreatic Cancer Cells. iScience 23, 101551. doi:10.1016/ j.isci.2020.101551

Lin, P., An, F., Xu, X., Zhao, L., Liu, L., Liu, N., et al. (2015). Chronopharmacodynamics and Mechanisms of Antitumor Effect Induced by Erlotinib in Xenograft-Bearing Nude Mice. Biochem. Biophys. Res. Commun. 460, 362-367. doi:10.1016/j.bbrc.2015.03.039
Lin, Y. M., Chang, J. H., Yeh, K. T., Yang, M. Y., Liu, T. C., Lin, S. F., et al. (2008). Disturbance of Circadian Gene Expression in Hepatocellular Carcinoma. Mol. Carcinog 47, 925-933. doi:10.1002/mc.20446

Litlekalsoy, J., Rostad, K., Kalland, K. H., Hostmark, J. G., and Laerum, O. D. (2016). Expression of Circadian Clock Genes and Proteins in Urothelial Cancer Is Related to Cancer-Associated Genes. BMC cancer 16, 549. doi:10.1186/ s12885-016-2580-y

Lu, H., Chu, Q., Xie, G., Han, H., Chen, Z., Xu, B., et al. (2015). Circadian Gene Expression Predicts Patient Response to Neoadjuvant Chemoradiation Therapy for Rectal Cancer. Int. J. Clin. Exp. Pathol. 8, 10985-10994.

Malaguarnera, R., Ledda, C., Filippello, A., Frasca, F., Francavilla, V. C., Ramaci, T., et al. (2020). Thyroid Cancer and Circadian Clock Disruption. Cancers (Basel) 12, 3109. doi:10.3390/cancers 12113109

Mullins, D., Proulx, D., Saoudi, A., and Ng, C. E. (2005). Chronomodulation of Topotecan or X-Radiation Treatment Increases Treatment Efficacy without Enhancing Acute Toxicity. Int. J. Radiat. Oncol. Biol. Phys. 62, 230-237. doi:10.1016/j.ijrobp.2004.12.084

Nakagawa, H., Koyanagi, S., Kuramoto, Y., Yoshizumi, A., Matsunaga, N., Shimeno, H., et al. (2008). Modulation of Circadian Rhythm of DNA Synthesis in Tumor Cells by Inhibiting Platelet-Derived Growth Factor Signaling. J. Pharmacol. Sci. 107, 401-407. doi:10.1254/jphs.08080fp

Nakagawa, H., Koyanagi, S., Takiguchi, T., Kuramoto, Y., Soeda, S., Shimeno, H., et al. (2004). 24-hour Oscillation of Mouse Methionine Aminopeptidase2, a Regulator of Tumor Progression, Is Regulated by Clock Gene Proteins. Cancer Res. 64, 8328-8333. doi:10.1158/0008-5472.CAN-04-2122

Nakagawa, H., Takiguchi, T., Nakamura, M., Furuyama, A., Koyanagi, S., Aramaki, H., et al. (2006). Basis for Dosing Time-dependent Change in the Anti-tumor Effect of Imatinib in Mice. Biochem. Pharmacol. 72, 1237-1245. doi:10.1016/ j.bcp.2006.08.002

Neilsen, B. K., Frodyma, D. E., McCall, J. L., Fisher, K. W., and Lewis, R. E. (2019). ERK-mediated TIMELESS Expression Suppresses G2/M Arrest in colon Cancer Cells. PLoS One 14, e0209224. doi:10.1371/journal.pone.0209224

Noh, J. M., Choi, D. H., Park, H., Huh, S. J., Park, W., Seol, S. W., et al. (2014). Comparison of Acute Skin Reaction Following Morning versus Late Afternoon Radiotherapy in Patients with Breast Cancer Who Have Undergone Curative Surgical Resection. J. Radiat. Res. 55, 553-558. doi:10.1093/jrr/rrt141

Ohdo, S., Koyanagi, S., and Matsunaga, N. (2019). Chronopharmacological Strategies Focused on Chrono-Drug Discovery. Pharmacol. Ther. 202, 72-90. doi:10.1016/j.pharmthera.2019.05.018

Okazaki, H., Matsunaga, N., Fujioka, T., Okazaki, F., Akagawa, Y., Tsurudome, Y., et al. (2014). Circadian Regulation of mTOR by the Ubiquitin Pathway in Renal Cell Carcinoma. Cancer Res. 74, 543-551. doi:10.1158/0008-5472.CAN-123241

Ozturk, N., Ozturk, D., Kavakli, I. H., and Okyar, A. (2017). Molecular Aspects of Circadian Pharmacology and Relevance for Cancer Chronotherapy. Int. J. Mol. Sci. 18, 2168. doi:10.3390/ijms 18102168

Padmanabhan, K., and Billaud, M. (2017). Desynchronization of Circadian Clocks in Cancer: A Metabolic and Epigenetic Connection. Front. Endocrinol. (Lausanne) 8, 136. doi:10.3389/fendo.2017.00136

Pagani, L., Schmitt, K., Meier, F., Izakovic, J., Roemer, K., Viola, A., et al. (2011). Serum Factors in Older Individuals Change Cellular Clock Properties. Proc. Natl. Acad. Sci. U S A. 108, 7218-7223. doi:10.1073/pnas.1008882108

Palombo, P., Moreno-Villanueva, M., and Mangerich, A. (2015). Day and Night Variations in the Repair of Ionizing-Radiation-Induced DNA Damage in Mouse Splenocytes. DNA Repair (Amst) 28, 37-47. doi:10.1016/ j.dnarep.2015.02.002

Panda, S., Hogenesch, J. B., and Kay, S. A. (2002). Circadian Rhythms from Flies to Human. Nature 417, 329-335. doi:10.1038/417329a

Papagiannakopoulos, T., Bauer, M. R., Davidson, S. M., Heimann, M., Subbaraj, L., Bhutkar, A., et al. (2016). Circadian Rhythm Disruption Promotes Lung Tumorigenesis. Cel Metab 24, 324-331. doi:10.1016/j.cmet.2016.07.001

Rahman, S., Kraljević Pavelić, S., and Markova-Car, E. (2019). Circadian (De) regulation in Head and Neck Squamous Cell Carcinoma. Int. J. Mol. Sci. 20, 2662. doi:10.3390/ijms20112662

Relles, D., Sendecki, J., Chipitsyna, G., Hyslop, T., Yeo, C. J., and Arafat, H. A. (2013). Circadian Gene Expression and Clinicopathologic Correlates in Pancreatic Cancer. J. Gastrointest. Surg. 17, 443-450. doi:10.1007/s11605012-2112-2 
Rivera-Reyes, A., Ye, S., E Marino, G., E Ciotti, G., Liu, Y., Posimo, J. M., et al. (2018). YAP1 Enhances NF-kb-dependent and Independent Effects on ClockMediated Unfolded Protein Responses and Autophagy in Sarcoma. Cell Death Dis 9, 1108. doi:10.1038/s41419-018-1142-4

Roche, V. P., Mohamad-Djafari, A., Innominato, P. F., Karaboué, A., Gorbach, A., and Lévi, F. A. (2014). Thoracic Surface Temperature Rhythms as Circadian Biomarkers for Cancer Chronotherapy. Chronobiol Int. 31, 409-420. doi:10.3109/07420528.2013.864301

Sathish Kumar, B., Kumar, A., Singh, J., Hasanain, M., Singh, A., Fatima, K., et al. (2014a). Synthesis of 2-alkoxy and 2-benzyloxy Analogues of Estradiol as Antibreast Cancer Agents through Microtubule Stabilization. Eur. J. Med. Chem. 86, 740-751. doi:10.1016/j.ejmech.2014.09.033

Sathish Kumar, B., Singh, A., Kumar, A., Singh, J., Hasanain, M., Singh, A., et al. (2014b). Synthesis of Neolignans as Microtubule Stabilisers. Bioorg. Med. Chem. 22, 1342-1354. doi:10.1016/j.bmc.2013.12.067

Scheving, L. E., Burns, E. R., Pauly, J. E., and Halberg, F. (1980). Circadian Bioperiodic Response of Mice Bearing Advanced L1210 Leukemia to Combination Therapy with Adriamycin and Cyclophosphamide. Cancer Res. 40, 1511-1515.

Shafi, A. A., and Knudsen, K. E. (2019). Cancer and the Circadian Clock. Cancer Res. 79, 3806-3814. doi:10.1158/0008-5472.CAN-19-0566

Shearman, L. P., Sriram, S., Weaver, D. R., Maywood, E. S., Chaves, I., Zheng, B., et al. (2000). Interacting Molecular Loops in the Mammalian Circadian Clock. Science 288, 1013-1019. doi:10.1126/science.288.5468.1013

Shinohara, A., Koyanagi, S., Hamdan, A. M., Matsunaga, N., Aramaki, H., and Ohdo, S. (2008). Dosing Schedule-dependent Change in the Disruptive Effects of Interferon-Alpha on the Circadian Clock Function. Life Sci. 83, 574-580. doi:10.1016/j.lfs.2008.08.005

Shuboni-Mulligan, D. D., Breton, G., Smart, D., Gilbert, M., and Armstrong, T. S. (2019). Radiation Chronotherapy-Clinical Impact of Treatment Time-Of-Day: a Systematic Review. J. Neurooncol. 145, 415-427. doi:10.1007/s11060-01903332-7

Singh, A., Fatima, K., Singh, A., Behl, A., Mintoo, M. J., Hasanain, M., et al. (2015). Anticancer Activity and Toxicity Profiles of 2-benzylidene Indanone lead Molecule. Eur. J. Pharm. Sci. 76, 57-67. doi:10.1016/j.ejps.2015.04.020

Singh, A., Fatima, K., Srivastava, A., Khwaja, S., Priya, D., Singh, A., et al. (2016). Anticancer Activity of Gallic Acid Template-Based Benzylidene Indanone Derivative as Microtubule Destabilizer. Chem. Biol. Drug Des. 88, 625-634. doi:10.1111/cbdd.12805

Singh, A., Mohanty, I., Singh, J., and Rattan, S. (2020). BDNF Augments Rat Internal Anal Sphincter Smooth Muscle Tone via RhoA/ROCK Signaling and Nonadrenergic Noncholinergic Relaxation via Increased NO Release. Am. J. Physiol. Gastrointest. Liver Physiol. 318, G23-g33. doi:10.1152/ ajpgi.00247.2019

Singh, A., Singh, J., and Rattan, S. (2021). Evidence for the Presence and Release of BDNF in the Neuronal and Non-neuronal Structures of the Internal Anal Sphincter. Neurogastroenterology Motil., e14099. doi:10.1111/nmo.14099

Soták, M., Sumová, A., and Pácha, J. (2014). Cross-talk between the Circadian Clock and the Cell Cycle in Cancer. Ann. Med. 46, 221-232. doi:10.3109/ 07853890.2014.892296

Srivastava, A., Fatima, K., Fatima, E., Singh, A., Singh, A., Shukla, A., et al. (2020). Fluorinated Benzylidene Indanone Exhibits Antiproliferative Activity through Modulation of Microtubule Dynamics and Antiangiogenic Activity. Eur. J. Pharm. Sci. 154, 105513. doi:10.1016/j.ejps.2020.105513

Stupp, R., Mason, W. P., van den Bent, M. J., Weller, M., Fisher, B., Taphoorn, M. J., et al. (2005). Radiotherapy Plus Concomitant and Adjuvant Temozolomide for Glioblastoma. N. Engl. J. Med. 352, 987-996. doi:10.1056/NEJMoa043330

Sulli, G., Lam, M. T. Y., and Panda, S. (2019). Interplay between Circadian Clock and Cancer: New Frontiers for Cancer Treatment. Trends Cancer 5, 475-494. doi:10.1016/j.trecan.2019.07.002

Takane, H., Ohdo, S., Yamada, T., Yukawa, E., and Higuchi, S. (2000). Chronopharmacology of Antitumor Effect Induced by Interferon-Beta in Tumor-Bearing Mice. J. Pharmacol. Exp. Ther. 294, 746-752.

Tang, Q., Cheng, B., Xie, M., Chen, Y., Zhao, J., Zhou, X., et al. (2017). Circadian Clock Gene Bmal1 Inhibits Tumorigenesis and Increases Paclitaxel Sensitivity in Tongue Squamous Cell Carcinoma. Cancer Res. 77, 532-544. doi:10.1158/ 0008-5472.CAN-16-1322
Tanimura, N., Kusunose, N., Matsunaga, N., Koyanagi, S., and Ohdo, S. (2011). Aryl Hydrocarbon Receptor-Mediated Cyplal Expression Is Modulated in a CLOCK-dependent Circadian Manner. Toxicology 290, 203-207. doi:10.1016/ j.tox.2011.09.007

To, H., Ohdo, S., Shin, M., Uchimaru, H., Yukawa, E., Higuchi, S., et al. (2003). Dosing Time Dependency of Doxorubicin-Induced Cardiotoxicity and Bone Marrow Toxicity in Rats. J. Pharm. Pharmacol. 55, 803-810. doi:10.1211/ 002235703765951410

Turek, F. W., and Allada, R. (2002). Liver Has Rhythm. Hepatology 35, 743-745. doi:10.1053/jhep.2002.32873

van der Watt, P. J., Roden, L. C., Davis, K. T., Parker, M. I., and Leaner, V. D. (2020). Circadian Oscillations Persist in Cervical and Esophageal Cancer Cells Displaying Decreased Expression of Tumor-Suppressing Circadian Clock Genes. Mol. Cancer Res. 18, 1340-1353. doi:10.1158/1541-7786.MCR-19-1074

Verlande, A., and Masri, S. (2019). Circadian Clocks and Cancer: Timekeeping Governs Cellular Metabolism. Trends Endocrinol. Metab. 30, 445-458. doi:10.1016/j.tem.2019.05.001

von Roemeling, R., and Hrushesky, W. J. (1989). Circadian Patterning of Continuous Floxuridine Infusion Reduces Toxicity and Allows Higher Dose Intensity in Patients with Widespread Cancer. J. Clin. Oncol. 7, 1710-1719. doi:10.1200/JCO.1989.7.11.1710

von Roemeling, R., and Hrushesky, W. J. (1990). Determination of the Therapeutic index of Floxuridine by its Circadian Infusion Pattern. J. Natl. Cancer Inst. 82, 386-393. doi:10.1093/jnci/82.5.386

Wang, F., Li, C., Luo, Y., and Chen, L. (2016). The Circadian Gene Clock Plays an Important Role in Cell Apoptosis and the DNA Damage Response In Vitro. Technol. Cancer Res. Treat. 15, 480-486. doi:10.1177/1533034615585433

Wang, Z., Wang, H., Guo, H., Li, F., Wu, W., Zhang, S., et al. (2020). The Circadian Rhythm and Core Gene Period2 Regulate the Chemotherapy Effect and Multidrug Resistance of Ovarian Cancer through the PI3K Signaling Pathway. Biosci. Rep. 40, BSR20202683. doi:10.1042/BSR20202683

Winter, S. L., Bosnoyan-Collins, L., Pinnaduwage, D., and Andrulis, I. L. (2007). Expression of the Circadian Clock Genes Per1 and Per2 in Sporadic and Familial Breast Tumors. Neoplasia 9, 797-800. doi:10.1593/neo.07595

Wood, P. A., Du-Quiton, J., You, S., and Hrushesky, W. J. (2006). Circadian Clock Coordinates Cancer Cell Cycle Progression, Thymidylate Synthase, and 5fluorouracil Therapeutic index. Mol. Cancer Ther. 5, 2023-2033. doi:10.1158/ 1535-7163.MCT-06-0177

Wu, Y., Sato, F., Yamada, T., Bhawal, U. K., Kawamoto, T., Fujimoto, K., et al. (2012). The BHLH Transcription Factor DEC1 Plays an Important Role in the Epithelial-Mesenchymal Transition of Pancreatic Cancer. Int. J. Oncol. 41, 1337-1346. doi:10.3892/ijo.2012.1559

Xiong, H., Yang, Y., Yang, K., Zhao, D., Tang, H., and Ran, X. (2018). Loss of the Clock Gene PER2 Is Associated with Cancer Development and Altered Expression of Important Tumor-Related Genes in Oral Cancer. Int. J. Oncol. 52, 279-287. doi:10.3892/ijo.2017.4180

Xu, Q., Ma, P., Hu, C., Chen, L., Xue, L., Wang, Z., et al. (2012). Overexpression of the DEC1 Protein Induces Senescence In Vitro and Is Related to Better Survival in Esophageal Squamous Cell Carcinoma. PLoS One 7, e41862. doi:10.1371/ journal.pone. 0041862

Xue, J., Dai, Y., Li, G., Lang, W., Li, P., Liu, Y., et al. (2020). DEC1 Directly Interacts with Estrogen Receptor (ER) a to Suppress Proliferation of ER-Positive Breast Cancer Cells. Biochem. Biophys. Res. Commun. 528, 740-745. doi:10.1016/ j.bbrc.2020.05.123

Yang, M. Y., Chang, J. G., Lin, P. M., Tang, K. P., Chen, Y. H., Lin, H. Y., et al. (2006). Downregulation of Circadian Clock Genes in Chronic Myeloid Leukemia: Alternative Methylation Pattern of hPER3. Cancer Sci. 97, 1298-1307. doi:10.1111/j.1349-7006.2006.00331.x

Yang, X., Wood, P. A., Ansell, C. M., Quiton, D. F., Oh, E. Y., Du-Quiton, J., et al. (2009). The Circadian Clock Gene Per1 Suppresses Cancer Cell Proliferation and Tumor Growth at Specific Times of Day. Chronobiol Int. 26, 1323-1339. doi:10.3109/07420520903431301

Ye, H., Yang, K., Tan, X. M., Fu, X. J., and Li, H. X. (2015). Daily Rhythm Variations of the Clock Gene PER1 and Cancer-Related Genes during Various Stages of Carcinogenesis in a golden Hamster Model of Buccal Mucosa Carcinoma. Onco Targets Ther. 8, 1419-1426. doi:10.2147/OTT.S83710

Yeh, C. M., Shay, J., Zeng, T. C., Chou, J. L., Huang, T. H., Lai, H. C., et al. (2014). Epigenetic Silencing of ARNTL, a Circadian Gene and Potential Tumor 
Suppressor in Ovarian Cancer. Int. J. Oncol. 45, 2101-2107. doi:10.3892/ ijo.2014.2627

Yoshida, K., Sato, M., Hase, T., Elshazley, M., Yamashita, R., Usami, N., et al. (2013). TIMELESS Is Overexpressed in Lung Cancer and its Expression Correlates with Poor Patient Survival. Cancer Sci. 104, 171-177. doi:10.1111/cas.12068

Yu, M., Li, W., Wang, Q., Wang, Y., and Lu, F. (2018). Circadian Regulator NR1D2 Regulates Glioblastoma Cell Proliferation and Motility. Oncogene 37, 4838-4853. doi:10.1038/s41388-018-0319-8

Zanger, U. M., and Schwab, M. (2013). Cytochrome P450 Enzymes in Drug Metabolism: Regulation of Gene Expression, Enzyme Activities, and Impact of Genetic Variation. Pharmacol. Ther. 138, 103-141. doi:10.1016/j.pharmthera.2012.12.007

Zappe, D. H., Crikelair, N., Kandra, A., and Palatini, P. (2015). Time of Administration Important? Morning versus Evening Dosing of Valsartan. J. Hypertens. 33, 385-392. doi:10.1097/HJH.0000000000000397

Zeng, Z. L., Luo, H. Y., Yang, J., Wu, W. J., Chen, D. L., Huang, P., et al. (2014). Overexpression of the Circadian Clock Gene Bmall Increases Sensitivity to Oxaliplatin in Colorectal Cancer. Clin. Cancer Res. 20, 1042-1052. doi:10.1158/ 1078-0432.CCR-13-0171

Zhanfeng, N., Yanhui, L., Zhou, F., Shaocai, H., Guangxing, L., and Hechun, X. (2015). Circadian Genes Per1 and Per2 Increase Radiosensitivity of Glioma In Vivo. Oncotarget 6, 9951-9958. doi:10.18632/oncotarget.3179

Zhang, Y. K., Yeager, R. L., and Klaassen, C. D. (2009). Circadian Expression Profiles of Drug-Processing Genes and Transcription Factors in Mouse Liver. Drug Metab. Dispos 37, 106-115. doi:10.1124/dmd.108.024174
Zhou, L., Luo, Z., Li, Z., and Huang, Q. (2020). Circadian Clock Is Associated with Tumor Microenvironment in Kidney Renal clear Cell Carcinoma. Aging (Albany NY) 12, 14620-14632. doi:10.18632/aging.103509

Conflict of Interest: The authors declare that the research was conducted in the absence of any commercial or financial relationships that could be construed as a potential conflict of interest.

The reviewer JZ declared a shared affiliation with several of the authors JZ, JW, QT to the handling editor at the time of the review.

Publisher's Note: All claims expressed in this article are solely those of the authors and do not necessarily represent those of their affiliated organizations, or those of the publisher, the editors, and the reviewers. Any product that may be evaluated in this article, or claim that may be made by its manufacturer, is not guaranteed or endorsed by the publisher.

Copyright (c) 2021 Zhou, Wang, Zhang and Tang. This is an open-access article distributed under the terms of the Creative Commons Attribution License (CC BY). The use, distribution or reproduction in other forums is permitted, provided the original author(s) and the copyright owner(s) are credited and that the original publication in this journal is cited, in accordance with accepted academic practice. No use, distribution or reproduction is permitted which does not comply with these terms. 